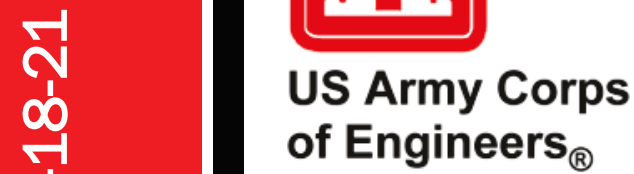

\title{
WERDC
}

Engineer Research and

Development Center

Installation Technology Transition Program (ITTP))

\section{Multi-fuel Combustion Technology for Water Heating with Waste Oil}

Joel Lindstrom and Scott M. Lux

September 2018

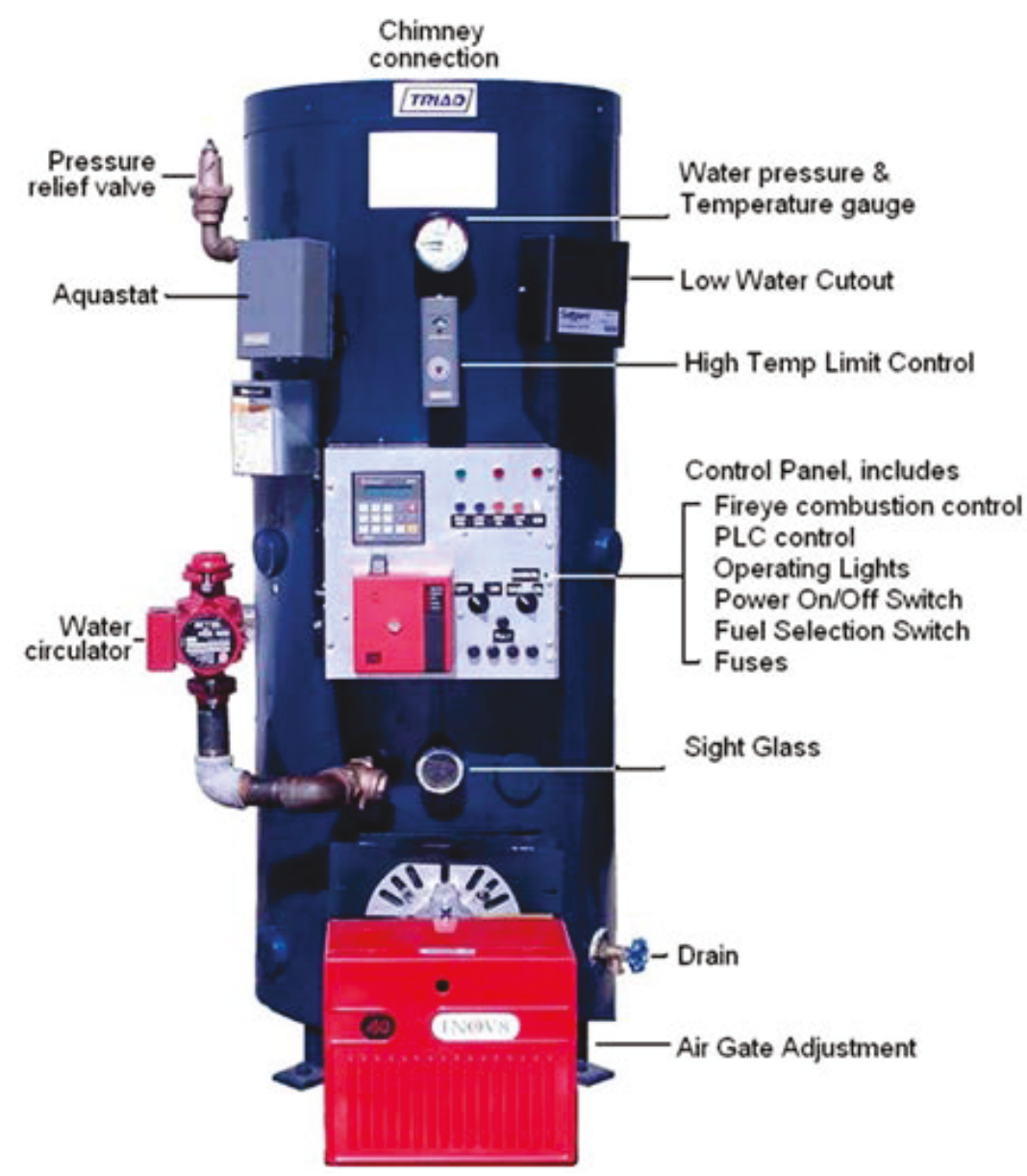

Approved for public release; distribution is unlimited. 
The U.S. Army Engineer Research and Development Center (ERDC) solves the nation's toughest engineering and environmental challenges. ERDC develops innovative solutions in civil and military engineering, geospatial sciences, water resources, and environmental sciences for the Army, the Department of Defense, civilian agencies, and our nation's public good. Find out more at www.erdc.usace.army.mil.

To search for other technical reports published by ERDC, visit the ERDC online library at http://acwc.sdp.sirsi.net/client/default. 


\section{Multi-fuel Combustion Technology for Water Heating with Waste Oil}

Scott M. Lux

Construction Engineering Research Laboratory (CERL)

U.S. Army Engineer Research and Development Center 2902 Newmark Dr.

Champaign, IL 61822-1076

Joel Lindstrom

Leonardo Technologies, Inc. (LTI)

70245 Bannock Uniontown Road

P.O. Box 178

Bannock, $\mathrm{OH}$ 43972-0178

Final Report

Approved for public release; distribution is unlimited.

\footnotetext{
Prepared for Office of the Assistant Chief of Staff for Installation Management (OACSIM) Washington, DC

Under Installation Technology Transition Program (ITTP), Project FY10-16E, "Energy Production from Straight Vegetable Oil," Work Unit CFE-B033
} 


\section{Abstract}

Joint Base Elmendorf-Richardson (JBER), Alaska, generates several thousand gallons of used vegetable oil (UVO) annually and expends over $\$ 10,000$ annually to dispose of this waste. Shipping excess UVO over long distances for processing is both expensive and wasteful, when it would be more efficient, economical, and effective to use UVO on site as a fuel to heat water. The Engineer Research and Development Center, Construction Engineering Research Laboratory (ERDC-CERL) and JBER began collaborating in December 2008 to investigate a solution to maximize the benefit of a 4000-gal annual production of UVO into a value-added commodity. This Phase II effort was undertaken to further develop and demonstrate the concept of using the UVO resource by using UVO as fuel for an advanced, multi-fuel water heater that would preheat domestic water entering the existing steam-water heating system in the building that houses the primary dining facility. This work designed a low maintenance UVO filtration and oil-burning system to support an opportunity assessment and pilot-scale implementation for the treatment and salvaging of UVO as a heating fuel at JBER.

DISCLAIMER: The contents of this report are not to be used for advertising, publication, or promotional purposes. Citation of trade names does not constitute an official endorsement or approval of the use of such commercial products. All product names and trademarks cited are the property of their respective owners. The findings of this report are not to be construed as an official Department of the Army position unless so designated by other authorized documents. 


\section{Contents}

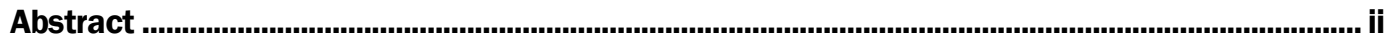

Figures and Tables........................................................................................................................

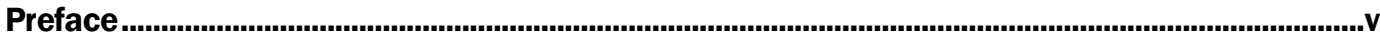

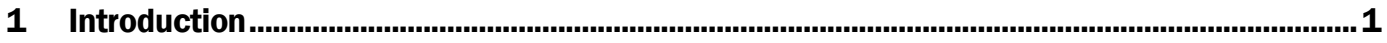

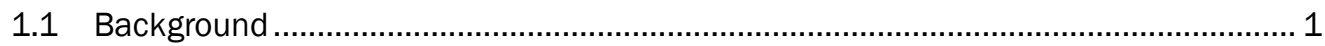

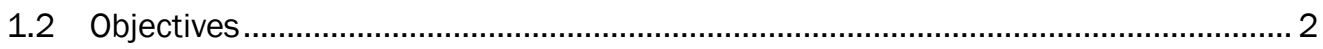

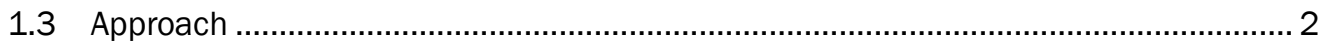

2 Used Vegetable Oil as a Heating Fuel......................................................................................4

2.1 INOV8 Multi-fuel water heater system ..................................................................... 5

2.2 Cost analysis of target system ...................................................................... 15

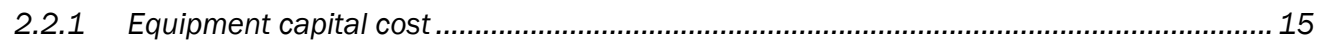

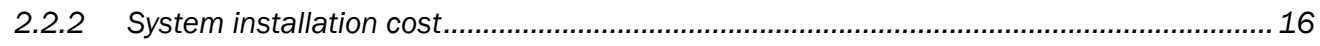

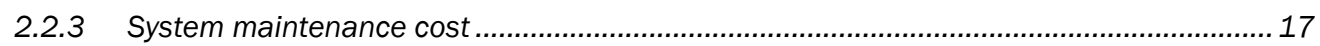

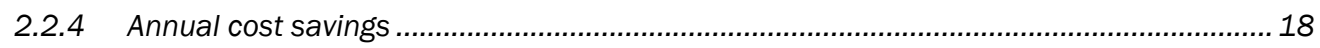

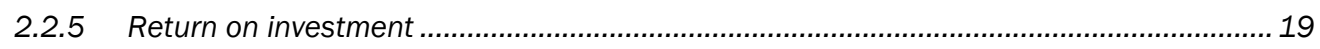

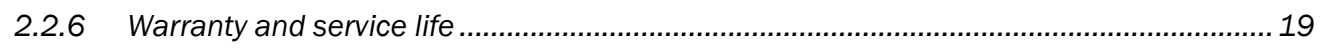

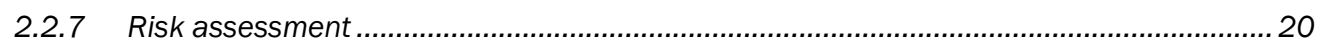

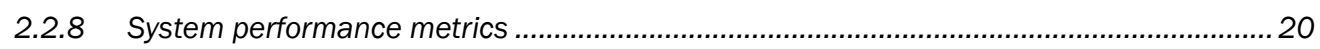

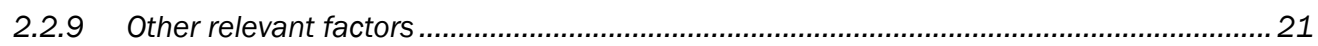

2.2.10 Sealed combustion versus atmospheric combustion ...................................................... 22

3 Proposed Equipment Installation at JBER .............................................................................23

3.1 Overview of proposed equipment installation.......................................................23

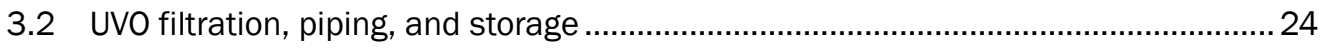

3.3 Domestic water tie-in and mechanical room layout.............................................29

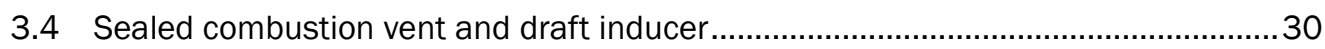

3.5 Cost of proposed equipment installation ............................................................36

3.6 Efforts to reduce the equipment installation cost ................................................38

3.7 Decision to abandon the proposed equipment installation .................................40

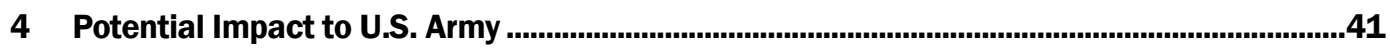

4.1 Facility compatibility .................................................................................... 41

4.2 Army and Air Force Exchange Service (AAFES) and Morale, Welfare, and Recreation (MWR)

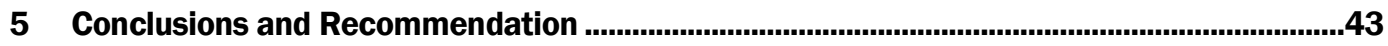

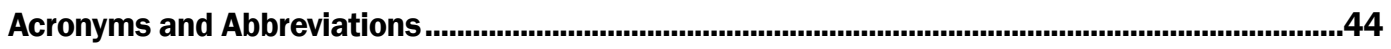

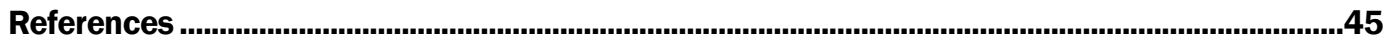

Appendix A: Multi-Fuel Water Heater Emissions Test Results .......................................................46

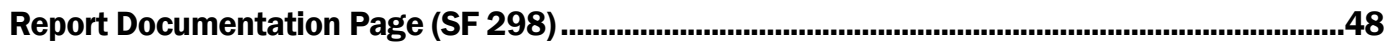




\section{Figures and Tables}

\section{Figures}

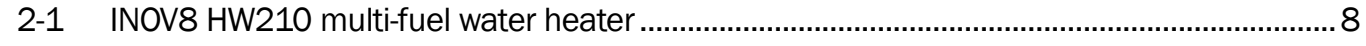

2-2 INOV8 gas-oil burner w/o cover .......................................................................................

2-3 Side view of INOV8 gas-oil burner ................................................................................

2-4 INOV8 multifuel water heater system .................................................................................12

2-5 Sealed combustion concentric vent system .......................................................................14

3-1 Fryer equipment in Bldg. 655 .........................................................................................26

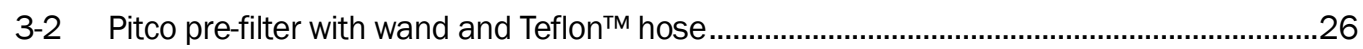

3-3 Schematic indicating UVO pump/filtration cart, hard pipe and storage tank ......................27

3-4 Schematic indicating domestic water tie-in and draft inducer ...........................................31

3-5 Available footprint for proposed multifuel water heater installation ...................................32

3-6 Indication of concentric sealed vent, combustion air boot and draft inducer .....................33

3-7 Tjernlund HS2 Power Venter performance curves...............................................................34

3-8 External wall shown with vent penetration and exhaust stack ...........................................35

3-9 Heatfab Saf-T Vent Cl Plus double wall vent.......................................................................39

\section{Tables}

2-1 INOV8 model HW210 water heater specifications ............................................................. 8

2-2 Multi-fuel water heater system capital cost (USD 2011) .......................................................16

2-3 Multi-fuel water heater system target installation cost ........................................................17

2-4 Multi-fuel water heater system annual maintenance cost ..................................................18

3-1 Itemized general contractor's quotation ..........................................................................38 


\section{Preface}

This study was conducted for the Office of the Assistant Chief of Staff for Installation Management (OACSIM) under the Installation Technology Transition Program (ITTP); Project FY10-16E, "Energy Production from Straight Vegetable Oil.” The ITTP Program Manager was Natalie R. Myers, CEERD$\mathrm{CNN}$, and the Technical Monitor was Wernher Heyres, DAIM-ODF.

The work was managed by the Energy Branch (CFE) of the Facilities Division (CF), Engineer Research and Development Center, Construction Engineering Research Laboratory (ERDC-CERL). Leonardo Technologies, Inc. (LTI) executed the engineering design and equipment installation under contract W9132T-09-C-0027. Giselle Rodriguez is Chief, CEERD-CFE, and Michelle J. Hanson is Chief, CEERD-CF. The associated Technical Director was Kurt Kinnevan, CEERD-CVT. The Deputy Director of ERDC-CERL was Dr. Kirankumar V. Topudurti and the Director was Dr. Lance D. Hansen.

COL Ivan P. Beckman was Commander of ERDC, and Dr. David W. Pittman was the Director. 
THIS PAGE INTENTIONALLY LEFT BLANK 


\section{Introduction}

\subsection{Background}

Joint Base Elmendorf-Richardson (JBER), Alaska, generates several thousand gallons of used vegetable oil (UVO) annually, at a cost of over $\$ 10,000$ annually to dispose of this waste. Currently, an onsite contractor collects all UVO from the dining facilities at JBER, stores the oil at a waste handling facility, after which the oil is shipped to Seattle for processing into biodiesel.

Shipping excess UVO over long distances for processing is both expensive and wasteful, when it would be more efficient, economical, and effective to use UVO on site as a fuel to heat water. Hot water is a mission-critical necessity. There is generally a need for hot water wherever UVO is produced. A commercially available multi-fuel water heater has been developed that can burn $100 \%$ UVO, co-fire UVO with natural gas or propane, and automatically switch to $100 \%$ gas when the UVO supply is disrupted. Assuming cold and hot water temperatures of 50 and $140^{\circ} \mathrm{F}$, respectively, 20 gal of UVO can provide roughly 2,450 gal of hot water, or $35^{\circ}$ gallons per day (GPD) for 7 days. At this production rate, the savings are considerable, from $\$ 1,000$ to $\$ 3$,000 per year depending on local fuel and maintenance costs.

ERDC-CERL and JBER began collaborating in December 2008 to investigate a solution to maximize the benefit of a 4000-gal annual production of UVO into a value-added commodity. In 2009, a pilot-scale implementation for the treatment and salvaging of UVO at JBER used filtered UVO as fuel in a modified diesel generator to provide electric power to the waste handling facility at JBER. Electric heating appliances were installed in Bldg. 45125 and were powered by the generator to offset the natural gas consumption of the existing warm air furnace (Lindstrom, Scott, and Jeff Raun 2010).

This initial collaboration was extended to a Phase II effort to further develop and demonstrate the concept of using the UVO resource at JBER. This concept would use UVO as fuel for an advanced, multi-fuel water heater that would preheat domestic water entering the existing steam-water heating system in the building that houses the primary dining facility. The retrofit install would use UVO pumping, filtration, and storage technologies to re- 
condition the oil for use in the advanced multi-fuel water heater. This implementation would demonstrate the use of UVO as a reliable fuel, thereby reducing UVO disposal costs while decreasing fossil energy consumption.

\subsection{Objectives}

The overall objective of this project was to develop a protocol for effective disposal and reuse of UVO as a heating fuel that can be implemented Army-wide. The specific objective of this work was to provide a low maintenance UVO filtration and oil-burning system to support an opportunity assessment and pilot-scale implementation for the treatment and salvaging of UVO as a heating fuel at JBER.

\subsection{Approach}

The objectives were accomplished in the following tasks

1. A site visit was made to JBER to determine a suitable demonstration site: JBER Bldg. 655, home of the Gold Rush Inn dining facility, was selected as the host site for the equipment demonstration. A high temperature filtration system was located in the frialator area in the primary dining facility, along with hard pipe installed to transport the UVO to a heated storage tank located in a basement mechanical room. The proposed location of the multi-fuel water heater was adjacent to the heated UVO tank.

2. UVO capable equipment manufacturers were evaluated and the candidate vendor was selected. Wisconsin-based INOV8 International Inc. was selected since its product line offers a programmable logic control (PLC) system, which enables co-firing of natural gas with UVO fuel, enables automatic purging of UVO fuel once daily to keep the burner head soot-free, and enables reliable operation in the event that UVO fuel supply is disrupted, whether due to a lack of UVO fuel or plugged filter. The INOV8 product has been subject to third party emissions testing and testing by safety compliance organizations such as the Underwriters Laboratory.

3. A retrofit multi-fuel water heater and filtration system design was developed incorporating commercial equipment where available, and including design and fabrication of customized equipment where necessary.

4. The UVO processing system was designed for use by operated and maintained by JBER personnel, to minimize footprint and maintenance requirements, and to include multiple safety and fail-safe controls within the multi-fuel water heater and filtration system. 
5. Initially, the multi-fuel water heater system was designed to consume UVO produced only in Bldg. 655; however, later design considerations were made to enable the future consumption of UVO produced throughout JBER.

6. Given the relatively large size of Bldg. 655's heating system, it was decided to use the multi-fuel water heater only to preheat domestic hot water entering the building's steam-domestic water heating system. The multi-fuel water heater would therefore reduce the steam requirements and ultimately the natural gas consumption of the existing boiler.

7. The UVO capable, multi-fuel water heater and filtration system was designed and fabricated for demonstration at the proposed JBER operation site over a period of 6 months, after which JBER could decide whether or not to retain and operate the equipment. However, due to retrofit complexity and cost consideration, the unit was not installed. 


\section{Used Vegetable Oil as a Heating Fuel}

Military bases often need to dispose of significant amounts of UVO as a result of food preparation by military staff. Each base is in charge of its own UVO disposal procedures; no standard protocol exists. The typical disposal method involves paying an offsite contractor or renderer collect the UVO. Over the past 5 years this service has come at no charge, and in some cases (per market conditions) the sale of UVO has been known to yield a modest source of revenue (as much as \$0.50/gal) (Revelos 2011, Gardin 2010).

However, this is not currently the case. Even when it is possible to sell excess UVO, the practice does not represent the most efficient or cost effective use of UVO. Military installations should consider using a low maintenance UVO filtration and oil-burning system to take advantage of the oil's high energy content. UVO constitutes an indigenous domestic resource that can be exploited as fuel for specifically designed fuel burners. The concept described here takes advantage of the high energy content of UVO $(\sim 130,000 \mathrm{Btu} / \mathrm{gal})$, burned at high efficiency ( $>80 \%$ lower heating value [LHV]) to produce hot water or low pressure steam. UVO can be used as an economically competitive renewable source of energy when used to fuel properly designed oil burner technology.

Traditionally, UVO has been disposed of and re-used in ways that do not fully take advantage of its high energy content. For example, UVO can be converted into biodiesel through a process that requires significant energy, water, chemical feedstock, and capital equipment investment. This method, even when subsidized up to $\$ 1.00 / \mathrm{gal}$, cannot produce fuel that is pricecompetitive in today's market. Biodiesel processing requires the use of hazardous, non-renewable feedstocks and yields a glut of contaminated glycerin. Moreover, its use as a transport fuel is less than half as energy efficient as the use of UVO as a heating fuel. This is further complicated by the fact that many of today's post combustion exhaust treatment systems cannot tolerate the use of any blend of biodiesel fuel due to its high flash point.

Probably the most widely applicable and effective means of re-using UVO is to burn it as a heating fuel-specifically, in an advanced water heater. The energy contained in the amount of UVO produced in a typical fast food restaurant is well matched to the energy required to satisfy the restaurant's demand for hot water. Furthermore, the use of a multi-fuel water 
heater is not affected by latitude or season, it is immune to the volatile UVO market, and does not produce additional site noise, vibration or combustion emissions. It does not require involvement by the local utility for establishing a net meter or power purchase agreement, as does the implementation of stationary power equipment. The multi-fuel water heater concept is easily duplicated, especially for new construction. Finally, the proposed multi-fuel water heater system stands to improve workplace environments by allowing kitchen personnel to eliminate manual handling and transport of hot and slippery UVO.

Wisconsin-based INOV8 International Inc. was selected as the equipment vendor for this FY10-16E Installation Technology Transition Program (ITTP) effort. The INOV8 HW210 multi-fuel water heater employs a PLC system that enables co-firing of natural gas with UVO, and facilitates a seamless transition to $100 \%$ natural gas when the UVO supply is exhausted. The INOV8 water heater technology has been demonstrated by multiple restaurant chain stores and is also tested and listed by IntertekETL-Semko. The INOV8 water heater technology has been found to significantly reduce fossil energy consumption, and to yield competitive economic paybacks. The multi-fuel water heater technology has been demonstrated in multiple private sector restaurants; however, it has not been evaluated for UVO disposal at military facilities.

\subsection{INOV8 Multi-fuel water heater system}

INOV8 International Inc. has 20+ years' experience in the design and installation of oil-burning equipment and has several multi-fuel water heater prototypes working in the field. Over the past several years INOV8 has developed a low pressure boiler/water heater (terms used interchangeably), in response to needs expressed by large, reputable fast food chain restaurants including Burger King, Buffalo Wild Wings and Culvers. Specifically, the fast food franchises have asked INOV8 for a water heater system that can continue reliable operation in the event that the UVO supply is disrupted. In response to these requirements, INOV8 developed a gas and oil capable burner equipped with a PLC. The multi-fuel burner system was also designed to accommodate the unique characteristics of fryer oil, specifically taking into account its extremely high flash point. The INOV8 technology also permits minimal UVO filtration, and the ability to customize burner and water heater controls. 
From practical experience INOV8 has found that the energy costs to produce domestic hot water in a medium-sized restaurant can be nearly eliminated with approximately 40 gal of UVO per week. Projections made for most private businesses report savings that cover the cost of the water heater equipment (and that include the various State and Federal tax credits and deductions) within 3-5 years. This rapid rate of return is in part attributed to the replacement of inefficient, corroded water heaters, and to a relatively high price of gas. However, it should be mentioned that although government agencies can qualify for some of the available tax credits, they do not pay income taxes and therefore cannot obtain the benefit of tax deductions. Thus, it will take longer for the multi-fuel water heater system to achieve an economic return on investment (ROI) for government agency installations.

The INOV8 multi-fuel burner technology is a commercial product, though certain areas of the system as a whole required optimization for this work. Specifically, the UVO filtration and storage systems, and the associated sensors and controls all required development to emerge from the prototype stage. Additionally, this work required the refinement of equipment operation and maintenance (O\&M) protocols for government facilities.

The use of UVO as a heating fuel has its challenges. The flash point of most vegetable oil ranges from 500 to $600{ }^{\circ} \mathrm{F}$, nearly double that of typical waste petroleum oils. Additionally the viscosity and surface tension of vegetable oil is significantly greater than that of petroleum oils. However, the energy content of vegetable oil is high, typically only 5-8\% less than that of fuel oil. Despite the presence of animal fats, the INOV8 technology does not emit residual smell or unburned oil when the equipment is properly installed and maintained.

INOV8 recommends the gas-oil burner with the PLC automated control if one or more of the following conditions exist: (1) available oil is less than 30 gal per week, (2) the oil has more than $3 \%$ water content, or (3) the user cannot risk loss of hot water.

INOV8 currently offers two multi-fuel water heaters, the HW210 and HW610, which use the Triad model 300 and 600 respectively. These boilers can provide a variety of heating needs and their small footprint is amenable to easy replacement of existing appliances. Their design encompasses a steel vertical fire tube boiler with a water-backed combustion chamber that is lined with a high temperature firebrick. INOV8 selected 
the Triad boiler given the hot combustion zone it creates for achieving optimal UVO combustion conditions. INOV8 has learned through experience that it is vital to provide a properly insulated, high temperature combustion zone to ensure complete UVO combustion.

Designed as a low pressure vessel, the Triad boiler has a pressure rating of 125 psig. Figure 2-1 shows the INOV8 boiler fully equipped, installed and wired with the following safety and operating controls

- Honeywell aquastat

- Honeywell low water cut-off

- combination pressure/temperature gauge

- relief valve

- high limit with manual reset.

Table 2-1 lists all INOV8 HW210 multi-fuel water heater specifications.

Since 1990, INOV8's patented waste oil burner technology has been used to preheat oil under high velocity conditions to prevent coking while removing any vapors created during the heating process. The novel waste oil burner technology is known to be effective at reducing or eliminating coking during fuel preheating, which is problematic for waste oil consumption as coke particles can easily plug fuel nozzles. Additionally, the system removes any vapors generated and delivers consistent oil pressure to the nozzle, thus providing stable and efficient operation. This, in combination with its high quality flame safeguarding, enables the INOV8 technology to provide a high level of safety and digital temperature control for easy adjustment.

INOV8's gas-oil "G-Series" burner shown in Figures 2-2 and 2-3 is used in the HW210 multi-fuel water heater. The "G-Series" burner has been tested certified by internationally recognized Intertek-ETL Semko to the following standards: American National Standards Institute (ANSI) Standard Z21.17/CSA 2.7-M98, Domestic Gas Conversion Burners (1998) and Canadian Standards Association (CSA) Standard B140.2.1-M98 Oil Burners Atomizing-Type (1990). 
Figure 2-1. INOV8 HW210 multi-fuel water heater.

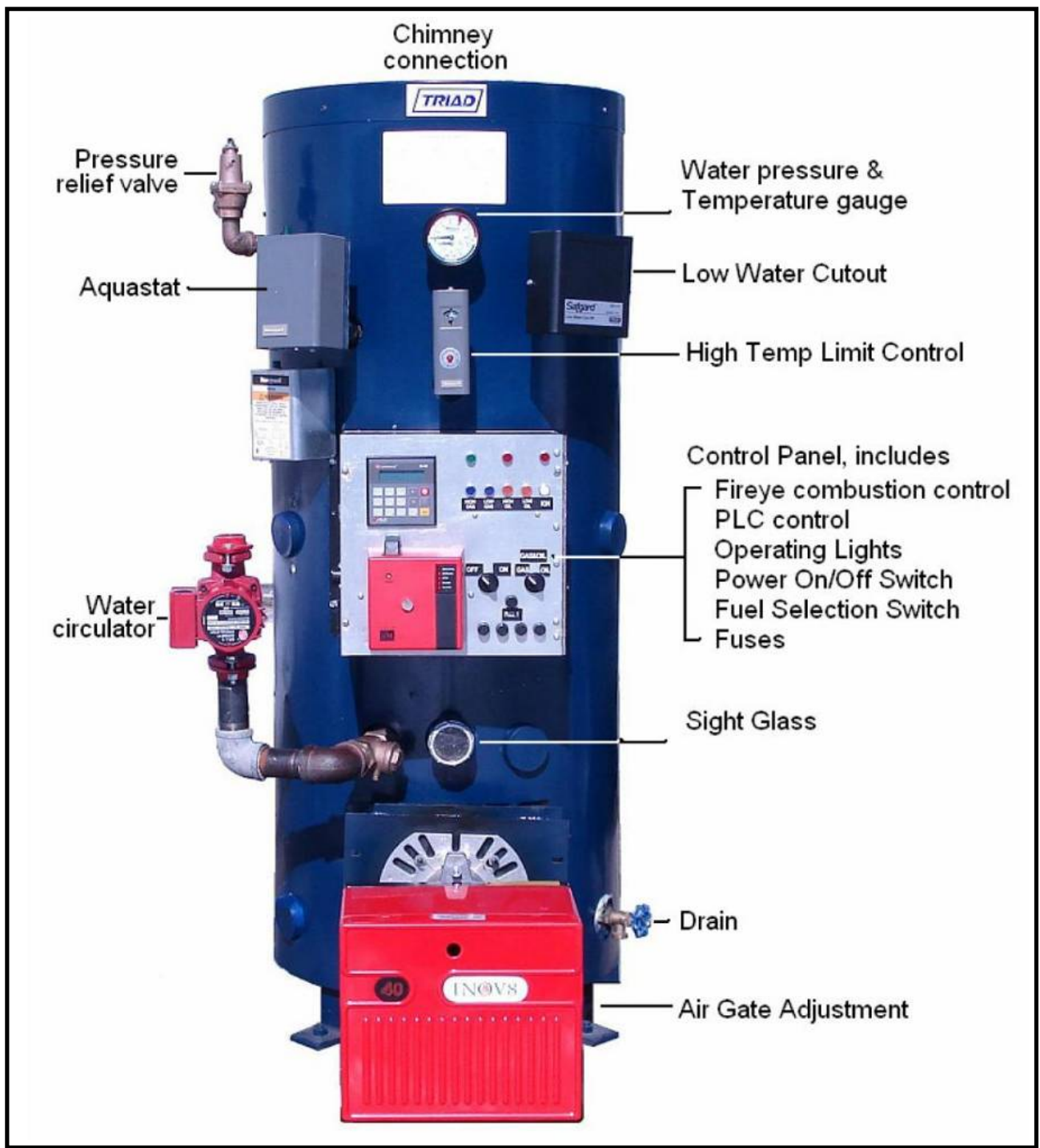

Table 2-1. INOV8 model HW210 water heater specifications.

\begin{tabular}{|l|l|}
\hline \multicolumn{1}{|c|}{ Water Heater Model Number } & \multicolumn{1}{c|}{ HW210 } \\
\hline Type & Commercial \\
\hline Water Volume & 35 \\
\hline Max Oil Consumption (gal/hr) & 1.53 \\
\hline Input (Btu/hr) & 210,000 \\
\hline Output (Btu/hr) & 174,400 \\
\hline Efficiency (\%) & 83 \\
\hline Chimney Diameter & 8 in. \\
\hline Supply \& Return Water Connections & 1.25 in. \\
\hline Jacket Diameter & 22 in. \\
\hline
\end{tabular}




\begin{tabular}{|l|l|}
\hline \multicolumn{1}{|c|}{ Water Heater Model Number } & \multicolumn{1}{c|}{ HW210 } \\
\hline Water Heater Height & 72.5 in. \\
\hline Height to Hot Water Connection & 60.75 in. \\
\hline Height to Cold Connection & 36.6 in. \\
\hline Gas Connection & $1 / 2$ in. \\
\hline Height to Gas Connection & 15 in. \\
\hline Manifold Gas Pressure & 0.71 to 3.0 \\
\hline Compressed Air Requirement & 2 cfm @ 35 psig \\
\hline Volts & 120 \\
\hline Amps & 20 \\
\hline Max. Vessel Pressure (PSIG) & 125 \\
\hline Flow Rate @100 ${ }^{\circ}$ F Rise-GPM / GPH & 3.49 / 209 \\
\hline Flow Rate @ 20 ${ }^{\circ}$ F Rise-GPM / GPH & $17.43 / 1046$ \\
\hline Shipping Weight-lbs. & 850 \\
\hline Operating Weight-lbs. & 1,140 \\
\hline
\end{tabular}

Figure 2-2. INOV8 gas-oil burner w/o cover.

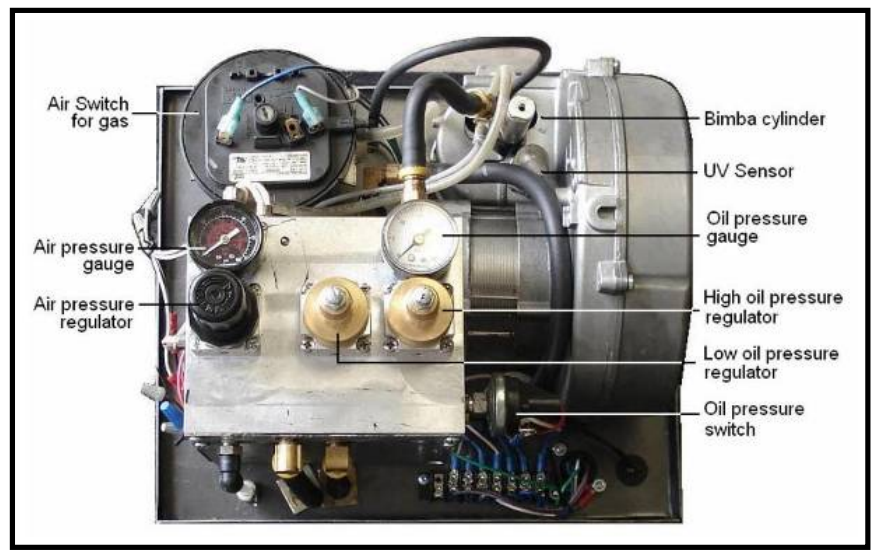

Figure 2-3. Side view of INOV8 gas-oil burner.

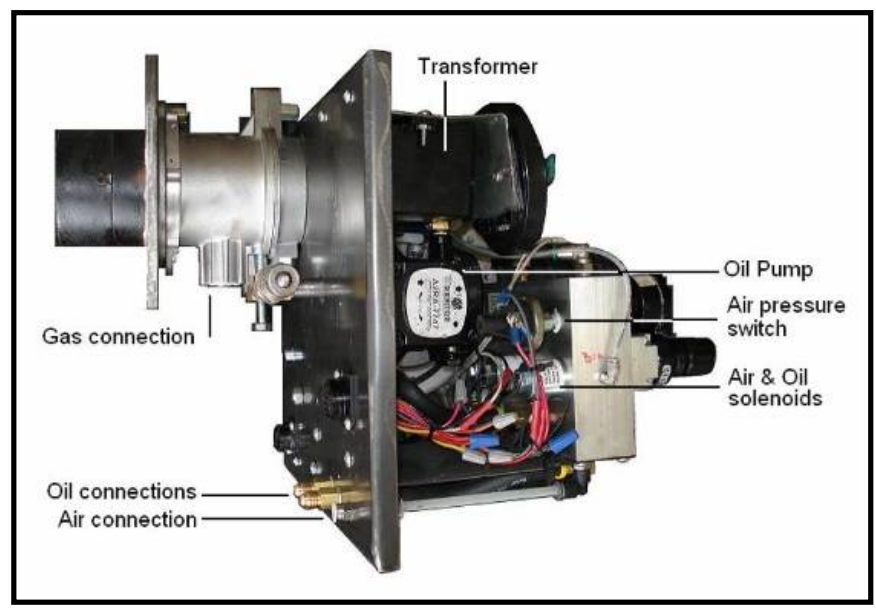


An advanced feature of the G-Series burner is that it has a needle that seats into the nozzle when the burner is not firing. It prevents oil from seeping out of the nozzle between firings to prevent nozzle coking and also aids in clearing any nozzle obstructions. Most waste oil burner appliances do not have such nozzle protection, and as such, nozzle blockages represent a significant issue for competing waste oil-burning appliances. The "G-Series" burner also has a vapor eliminator/pressure relief assembly that serves three functions

1. It vents any vapors that accumulate in the burner's oil circulating system back to the oil supply tank.

2. It filters the oil as it is heated and re-circulated at the burner.

3. It shunts the full volume of the pump back to the tank in the event the vapor eliminator filter should become plugged.

The burner is also set up with a self-priming pump that will draw the oil to itself and provides for the patented recirculation function of the oil heater. Combustion tests with INOV8 burner technology have been shown to yield very low carbon monoxide $(\mathrm{CO})$ readings, low chimney temperatures, smoke patch tests of zero or one, and efficiencies ranging from 82 to $91 \%$. Appendix A Emissions data for operation on UVO and other heavy oils can be found in.

As mentioned, another major advantage of the INOV8 product line is that employs a PLC system that enables the co-firing of natural gas or propane with UVO. A PLC is essentially a small computer that can be used to control equipment by turning on and off outputs based on specified input conditions. INOV8 has written programs that monitor and control switches, solenoids, valves and a temperature sensor in the gas-oil burner. The result is a burner with automated fuel selection based on the availability of waste oil and/or individual operator preferences. A basic list of functions of INOV8's PLC program includes:

1. The INOV8 PLC program monitors the oil temperature and assures that it reaches a pre-set level before allowing UVO to be used as fuel. Once the pre-set temperature is reached, the PLC energizes the air and oil solenoid valves, allowing oil to flow to the nozzle for atomization and combustion. 
2. Based on the fuel selection, the PLC controls two oil solenoids: One to control the oil flow at $50 \%$ of the desired Btu value, and a second to control the oil flow at $100 \%$ of the Btu value.

3. Based on the fuel selection, the PLC also monitors and controls two gas valves: one to control the gas pressure at $50 \%$ of the desired Btu value, and a second to control the gas pressure at $100 \%$ of the Btu value.

4. The PLC does self-checking of the fuel valves in the burner to assure they are performing as intended. The PLC runs parameter scans multiple times per second.

5. The PLC works in conjunction with the flame safety control to monitor all operational circumstances.

6. The PLC is connected to an oil pressure switch that will deliver a signal if oil pressure is lost due to a blockage, dirty filter or absence of oil. The PLC then reverts the fuel supply to full gas pressure and provides a signal to the operator that the oil supply must be corrected or replenished.

7. The PLC allows for operator input for customizing settings. Other options such as auto restart after power failure can be set as desired. Two examples are that:

a. The oil temperature can be raised or lowered as needed (per UVO characteristics, hydrogenated, non-hydrogenated, etc.).

b. The over-lap time of running gas and oil can be shortened or lengthened as needed.

8. The PLC enables the automatic purging of UVO fuel once weekly, to ensure the burner head is kept free of soot and excessive maintenance.

9. The PLC also has an algorithm to detect a "low air" condition to protect against an air inlet constriction or dirty draft.

The INOV8 PLC control panel has been tested and listed to UL 873 Safety for Temperature-Indicating and Regulating Equipment, $11^{\text {th }}$ ed. dated December 1994 and CSA C22.2 No. 24-03.

As shown in Figure 2-4, the complete INOV8 multi-fuel water heater system consists of a PLC-controlled, multi-fuel water heater, an air compressor, a UVO tank with fill level and feedback controls, and a UVO cartridge filter assembly with associated pump and transport lines.

The multi-fuel water heater system uses two air supplies. Air entering the combustion chamber through the burner housing is referred to as "combustion air." Pressurized air supplied to the fuel nozzle to lift the nozzle 
pin is referred to as "atomizing air." A conventional shop-type air compressor is used to supply atomizing air.

Figure 2-4. INOV8 multi-fuel water heater system.

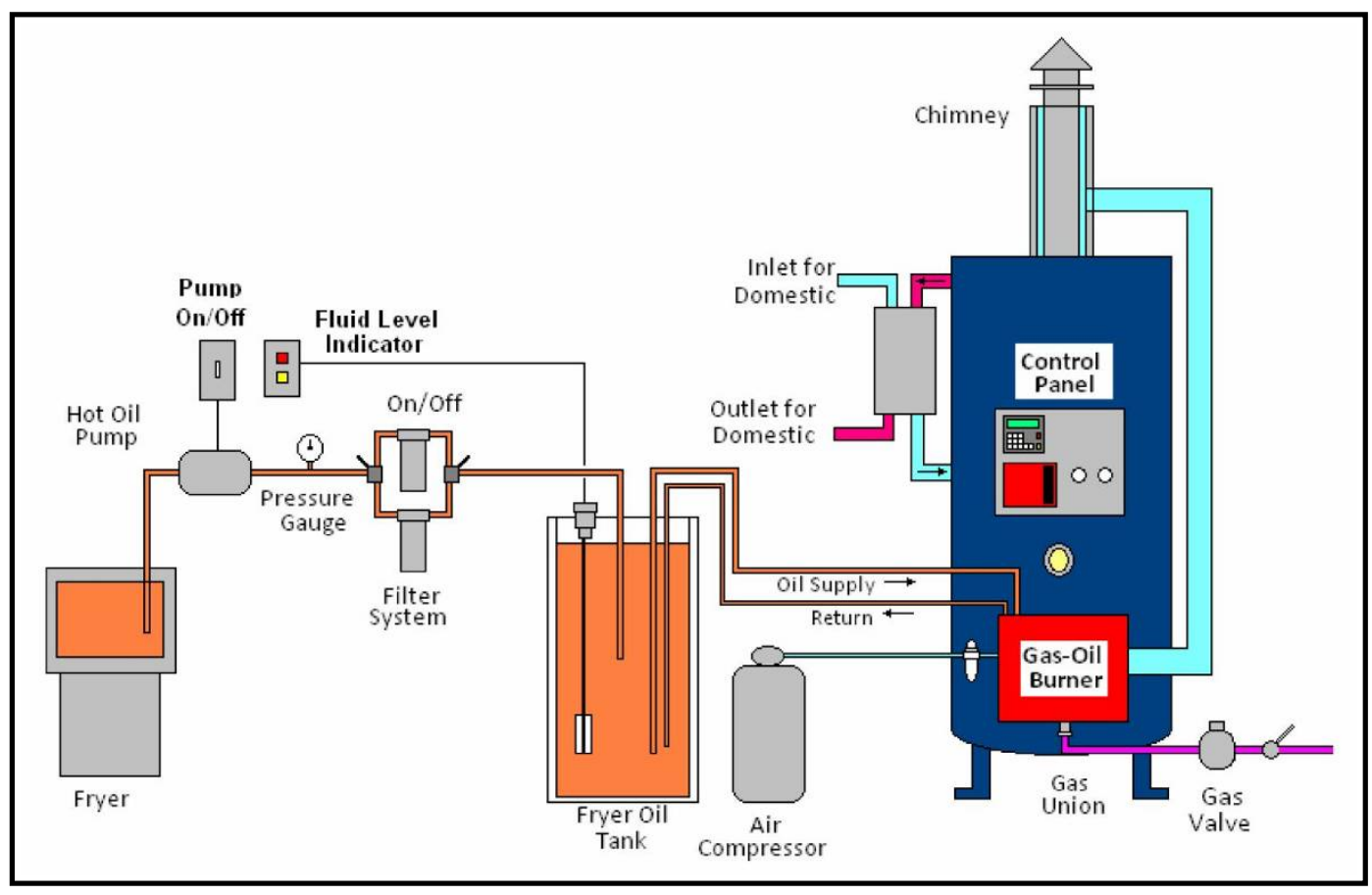

In case a UVO cartridge filter becomes plugged during a fryer drain, two filters are configured in parallel to make sure that the UVO is completely drained. The filters are used only one at a time and are isolated with a three-way valve that is instrumented with a pressure gauge to notify the user of a plugged filter. Ideally, the frialator drains are hard-piped to the filtration system. If this is not possible, a stainless steel pickup wand is used to extract UVO from the frialators. The pickup wand is then connected to the self-priming pump via Teflon hose.

A switch is used to open a valve and to run the pump/filtration system. The filtered oil is pumped directly into the UVO storage tank located (ideally) adjacent to the water heater. A tank fill level indicator is located near the pump switch, which indicates the approximate fluid level of the tank. Red and yellow indicator lights relay half-full and full tank readings to the pump operator. If the operator fails to detect that the storage tank is full while pumping UVO, the system will automatically stop the pump's operation to prevent the tank from overfilling. 
Ideally, UVO should be drained and filtered while it is still hot, i.e., above $200{ }^{\circ} \mathrm{F}$, to prevent the cartridge filters from prematurely plugging. Since many frialators do not display oil temperature once they are shut off, it is advised to drain and filter UVO shortly after shutoff before the UVO cools down, when viscosity and surface tension substantially increases. This means that UVO at temperatures of up to $400^{\circ} \mathrm{F}$ may pass through the filtration system and into the storage tank. Therefore, all filtration and storage tank equipment and gaskets were designed to exhibit high temperature resistance and chemical compatibility with UVO.

Food debris in fryer oil will settle out within a couple of days if the oil is kept over $120^{\circ} \mathrm{F}$. This is one of the reasons why a hot water loop is circulated between the multi-fuel water heater and UVO storage tank. To promote gravity separation of fines and also to preheat the UVO fuel, the water heater system uses a hot water circulation loop to maintain the UVO storage tank at $120-140^{\circ} \mathrm{F}$. If UVO is not given sufficient time to settle, but allowed to cool, then food debris will be difficult to remove and will cause premature filter blockages. Thus, warm filtering of the oil and sufficient settling time are vital to achieving low filtration system maintenance. Filter maintenance requirements must be developed onsite, which are a function of UVO throughput, solids loading, filtration temperature and filter cartridge area. Filtration system maintenance intervals can vary widely, where monthly cleaning of filter cartridges is generally anticipated.

Water heater vent systems must be installed per National Fire Protection Association (NFPA) 31: Installation of Oil-Burning Equipment (2011) and to all local codes. Safe operation of combustion heating equipment requires a properly operating vent system, correct provision for combustion air, and regular maintenance and inspection. Most National and state codes recommend that a "Class A" stainless steel lined insulated chimney be used from a point $18 \mathrm{in}$. below the ceiling to the top of the rain cap. The purpose of the insulated chimney is to protect combustible building materials from high temperature, but also to support the chimney draft and to help prevent harmful condensation by keeping exhaust temperatures high. Water vapor can condense inside the chimney during cold weather, exposing the vent system to severe degradation. 
The multi-water heater requires the installation of a sealed combustion, concentric vent exhaust system (Figure 2-5). This is necessary so as to preheat combustion air significantly, to help maintain a high temperature in the combustion chamber. INOV8 specifies that a 6-in. duct be used within an 8-in. duct; exhaust gases flow within the inner duct. The incoming fresh air flows in the annulus in which a combustion air standoff must be installed to draw the heated air into a 4-in. duct that leads to the burner. Ideally, the combustion air is preheated to $200-250^{\circ} \mathrm{F}$.

Figure 2-5. Sealed combustion concentric vent system

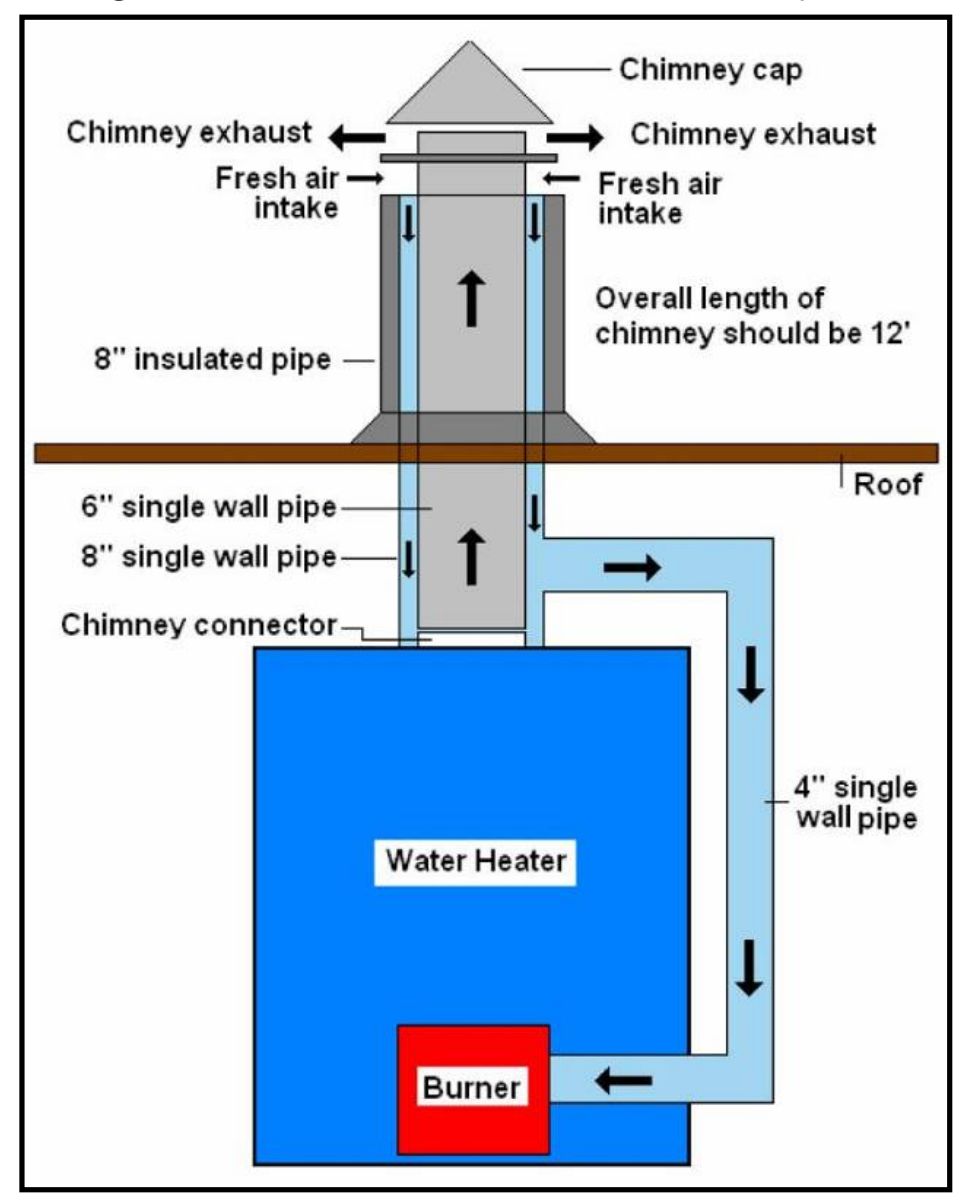

The concentric duct must also be connected to the water heater in such a way that it can be easily removed or swung out of the way for cleaning. Stack temperatures of 300 to $400{ }^{\circ} \mathrm{F}$ will be observed and thus the vent must be installed with proper clearances from combustible surfaces. The stack must also be installed to a sufficient height above the roofline to avoid down drafts. The last stack section must extend at least $3 \mathrm{ft}$ above the highest point at which it comes in contact with the roof, and at least 
$2 \mathrm{ft}$ higher than any ridge, parapet wall or roof structure within $10 \mathrm{ft}$ of the chimney. A non-restrictive rain cap should be installed on top of the stack. A Breidert cap is recommended in extremely windy locations. The vent shown in Figure 2-5 is the simplest, most ideal sealed combustion concentric vent configuration.

The combustion exhaust vent system is sealed and thus there is no possibility of back draft; however, there is also no barometric draft control. Explosion protection, that is the use of a double acting barometric draft control, must be installed when natural gas or propane may be used.

INOV8 specifications require that a negative pressure of -0.02 to -0.04 inches water must always be maintained in the combustion chamber. The draft should be measured only after the installation is complete and the burner is operating long enough for the water heater to get up to temperature. In some installations, it is necessary to install a draft inducer to offset any additional pressure drop imposed by bends and/or long vent sections, excessive cooling of exhaust, or by the accumulation of ash or soot. A draft inducer is a motordriven fan that attaches to the chimney to augment the natural draft of that chimney. Use of a draft inducer is not a cure-all or ideal, as it provides no relief for resonation problems that can occur in horizontal runs.

There are several other potential issues as well, aside from the capital expenditure and potential failure/maintenance requirements of the additional equipment. The multi-fuel water heater system also requires a dedicated 20-amp ground fault protected circuit breaker, namely for the burner, oil heater and regulator assembly, the oil pump motor and the hot water loop pump motor. The following section evaluates the capital investment, installation cost, maintenance cost, ROI, warranty, risk, and other relevant factors pertaining to an ideal or target multi-fuel water heater system.

\subsection{Cost analysis of target system}

\subsubsection{Equipment capital cost}

The capital cost of the INOV8 HW210 water heater, air compressors, oil pump/controls, filter assembly and oil storage/containment system currently adds up to approximately $\$ 17,500$ (Table $2-2$ ). Some of this equipment is emerging from the prototype stage and thus a target cost for this equipment is also shown, most notably for the UVO storage tank assembly. 
Specifically, the cost of the UVO storage system is expected to fall based on the substitution of fewer and lower cost components. Note that these figures do not include sales tax or freight, where freight is expected to be $\$ 300$ to $\$ 500$, depending on destination and the need for a lift gate.

Table 2-2. Multi-fuel water heater system capital cost (USD 2011).

\begin{tabular}{|l|c|c|}
\hline \multicolumn{1}{|c|}{ Component } & Current Capital Cost & Target Capital Cost \\
\hline Multi-fuel Water Heater HW210 & $\$ 9,750$ & $\$ 9,750$ \\
\hline Air Compressors (2) & $\$ 500$ & $\$ 400$ \\
\hline UVO Pump and Controls & $\$ 875$ & $\$ 875$ \\
\hline UVO Filtration Assembly & $\$ 1,325$ & $\$ 1,325$ \\
\hline UVO Storage Tank Assembly & $\$ 3,950$ & $\$ 1,000$ \\
\hline UVO Pickup and Hoses (2) & $\$ 1,100$ & $\$ 650$ \\
\hline Equipment Capital Cost & $\$ 17,500$ & $\$ 14,000$ \\
\hline
\end{tabular}

\subsubsection{System installation cost}

The cost and complexity of the multi-fuel water heater system installation will vary. In the simplest case, the entire installation is expected to take as little as 16 work-hours, including the installation of a custom concentric combustion air/exhaust vent. In the most complex installations, it may take as many as 150 work-hours, where the cost of a mechanical contractor is typically $\$ 100$ per hour. The installation of the concentric vent and flue stack poses the greatest variability, where it can become complex and expensive when the vent system necessitates a positive indoor exhaust pressure, warranting the soldering or welding of indoor vent seams. Additionally, per outdoor climate conditions and vent length, part or all of the exhaust vent may need to be insulated. Any core drilling requirements for retrofit installations also increase cost. For this and other reasons, retrofit installations are generally considered more expensive than new construction.

Water heater installations done to supplement larger heating systems (as opposed to replacing the primary water heating appliance), can also add cost due to the additional domestic water plumbing and core drilling requirements. Furthermore, the installation of a complex vent system may not allow the consumption of $100 \%$ UVO, and may even limit the UVO cofire ratio to below $50 \%$, which can limit the payback of some installations. New construction or the replacement of an existing/primary water heater at the end of its useful life is clearly the most ideal scenario, which will be referred to as a "target installation." 
Table 2-3 summarizes the estimated installation cost for a target installation, where a spent water heater is replaced with the multi-fuel water heater. These costs do not include the use of a mechanized dolly or man lift, where necessary. It is assumed that the old water heater and vent is disposed of without cost due to its value as scrap metal. The sum of capital costs and total installation costs comes to $\$ 16,500$. The installed cost of a conventional gas-fired water heater with comparable efficiency, warranty, and service life is estimated as $\$ 6,500$. The additional upfront cost of the multi-fuel water heater system is $\$ 10,000$.

Table 2-3. Multi-fuel water heater system target installation cost.

\begin{tabular}{|l|c|}
\hline \multicolumn{1}{|c|}{ Component } & Target Install Cost \\
\hline Water Heater Replacement/Gas, Water and Electric Hookup & $\$ 1,000$ \\
\hline Custom Concentric Vent, Combustion Air Standoff and Insulation & $\$ 500$ \\
\hline UVO Hard Piping, Insulation, Valve/Disconnect and Controls Wiring & $\$ 500$ \\
\hline Target Equipment Installation Cost & $\$ 2,000$ \\
\hline
\end{tabular}

\subsubsection{System maintenance cost}

Given the disposal of 20 gal UVO per week, the target maintenance requirement for the multi-fuel water heater system is estimated as 2 workhours every 2 months, for cleaning the UVO filtration cartridges and to conduct a visual inspection of all associated equipment. The UVO storage tank will also require annual maintenance, namely to remove any buildup of water or fines (particles) that may settle to the bottom. The bi-monthly filter and annual tank cleaning can be performed by any trained personnel, and thus its cost will depend on site-specific labor rates. The multi-fuel water heater also requires annual maintenance by a qualified heating, ventilating, and air-conditioning (HVAC) technician, to inspect the exhaust vent and burner head, and to adjust the associated controls and settings if necessary. This annual service is estimated at $\$ 250$, and assuming a nominal site-specific labor rate of $\$ 20$ per hour, the target maintenance cost is estimated at $\$ 570$ per year. Table 2-4 itemizes the maintenance cost estimates. It is assumed that $\$ 50$ per year is spent on maintaining a natural gas-fired water heater, and that the additional maintenance cost of the multi-fuel water heater system is $\$ 520$ per year. 
Table 2-4. Multi-fuel water heater system annual maintenance cost.

\begin{tabular}{|l|c|}
\hline Component & Annual Maintenance Cost \\
\hline Bi-monthly filter cleanse and visual inspection $(\$ 20 / \mathrm{hr})$ & $\$ 240$ \\
\hline UVO storage tank cleanse $(\$ 20 / \mathrm{hr})$ & $\$ 80$ \\
\hline Water heater inspection and adjustment (technician) & $\$ 250$ \\
\hline Target annual maintenance cost & $\$ 570$ \\
\hline
\end{tabular}

\subsubsection{Annual cost savings}

Assuming cold and hot domestic water temperatures of 50 and $140{ }^{\circ} \mathrm{F}$ respectively, 20 gal of UVO can provide approximately 2,450 gal of hot water, or 350 GPD for 7 days. This calculation includes standby heat losses from the water heater, UVO tank, and from the hot water piping. Assuming that the delivered natural gas is $\$ 1.00$ per therm (U.S. average in 2011), and also an avoided UVO disposal cost of $\$ 0.25 /$ gal, then a system that uses 20 gal of UVO per week would yield a monthly savings of $\$ 130$. These figures assume equivalent before and after water heater efficiencies of $82 \%$, and also they do not account for cost savings due to the potential for reduced space air-conditioning requirements resulting from the use of the multi-fuel water heater's sealed combustion system. The calculated cost savings also assume that there is sufficient demand for hot water and that all of the UVO is consumed. In practice it is generally observed that restaurants and dining facilities have sufficient hot water demand to consume all of the UVO produced.

Given all of the mentioned assumptions a gross annual cost savings of $\$ 1560$ is expected. Subtracting the additional cost of maintaining the multifuel water heater system, derives a net annual cost savings of $\$ 1,040$. It is quite easy to use the demonstrated example to calculate cost savings using different gas prices, labor rates, or cost/benefit of UVO disposal.

The use of UVO as a fuel can yield other benefits beyond simple cost savings. Electing to remove UVO from the fryer area via hard pipe yields a safer, cleaner, more efficient work environment. An even safer work environment can be achieved by installing a water heater with a sealed combustion system, which would be unaffected by the powerful exhaust fans typically used in restaurants and dining facilities. Such large exhaust fans can create substantially negative building pressures, making atmospheric combustion appliances highly susceptible to backdraft and potentially flame rollout, especially when these appliances are not isolated in properly 
designed mechanical rooms or appliance closets. Backdraft conditions pose a significant risk to building occupants through carbon monoxide poisoning, and flame rollout conditions can cause fire.

\subsubsection{Return on investment}

Assuming that the installed cost of the multi-fuel water heater system is $\$ 16,500$, and that the installed cost of a typical natural gas-fired water heater with comparable efficiency, warranty, and service life is $\$ 6,500$, then the additional upfront cost is taken as $\$ 10,000$. Without considering the time-value of money or tax credits and deductions, the target installation is expected pay for itself by the $10^{\text {th }}$ year for government installations (given $\$ 1.00$ per therm natural gas), with the potential to yield significant fuel and UVO disposal savings for another 10 and perhaps 20 years. As implied, with proper maintenance, the high quality, multi-fuel water heater system is expected to last 20 and perhaps 30 years.

While it is difficult to ascertain if the multi-fuel water heater system will be installed in a private or government-owned building, it is assumed that any equipment installed in a government-owned building cannot be used to decrease tax liability, as government agencies typically do not pay income tax. Government agencies may qualify for economic incentives for installing renewable energy technologies, though it is likely that tax liability reduction methods such as depreciation do not apply to the present analysis. Such tax liability factors and incentives make a marked difference regarding the economic payback of any high efficiency or renewable energy equipment installation.

In the private sector, the depreciation of the target multi-fuel water heater system equipment is estimated to be $\sim \$ 330$ per year, given a 10-year depreciation schedule. This cannot be compared directly to the use of a conventional water heater, the installation and operating costs of which can also be used to decrease tax liability. The economic payback analysis is simplified when the equipment is installed by a government agency. However the ROI is much longer.

\subsubsection{Warranty and service life}

Commercial water heaters with higher capital cost generally come with warranty coverage significantly better than that of lower cost (and lesser 
quality) units. The capital cost of a similar size, albeit much lower quality water heater can be as low as $\$ \mathbf{2 7 5 0}$; however, its warranty may only last 1 year for parts and 3 years for the tank/tubes. Additionally, many lower cost commercial units have warranties that become void if the defunct unit is found to have excessive scale due to a lack of proper maintenance or lack of water softener. On average, such low quality water heaters provide only 5 to 7 years of service life. As noted, the service life of any water heating appliance is substantially prolonged by proper maintenance, and also by the use of a water softener (where necessary). However, the quality of construction is also a major factor relating to water heater service life. The long service life of the Triad boiler used in the INOV8 HW210 is attributed to the use of high grade steel instead of copper, where its warranty covers 2 years for parts and 10 years for the tubes.

For these reasons it is strongly recommended to use anti-freeze in water heaters that have a separate, internal heating loops. Use of anti-freeze prevents rust scaling and corrosion, which can reduce water heater output as much as $30 \%$ in a short period of time.

\subsubsection{Risk assessment}

The use of any oil-burning equipment increases the risk for chimney fire, and when a long vent system is required the multi-fuel water heater vent system may yield a significant potential for the formation of condensate in the flue stack (especially in cold weather climates). This risk is partly managed by the PLC control used by the multi-fuel water heater, which will shut itself down in the event of low air flow conditions. And given the pumping and filtering of hot UVO, and storage of warm UVO, there may be an increased risk for UVO spillage. This risk is partly managed by the use of a secondary containment (overpack) drum around the UVO storage tank, and by having redundant control systems that interface the UVO pump/filter/storage equipment.

\subsubsection{System performance metrics}

Assuming the multi-fuel water heater consumes 20 gal/wk UVO and operates for $52 \mathrm{wk} / \mathrm{yr}$, an annual natural gas energy savings of about 1,300 therm (or 38,00o $\mathrm{kWh}$ ) can be expected. These assumptions equate to a natural gas-baseline $\mathrm{CO}_{2}$ emission abatement of about $15,500 \mathrm{lb}$ (or 7,030 
$\mathrm{kg}$ ) per year. Furthermore, given a total installed cost of $\$ 16,500$, the capital cost of the multi-fuel water heater system is very competitive at about $\$ 280$ per $\mathrm{kW}$. Moreover, without considering the time-value of money and tax ramifications, the equivalent heating cost of the target installation is extremely competitive at about $\$ 7.50$ per MMBTU (\$0.026 per kWh).

\subsubsection{Other relevant factors}

In some cases a restaurant or dining facility may heat water with more expensive fuels such as propane, which has an average cost of $\$ 3.00$ per therm $(\$ 2.80 / \mathrm{gal})$ in the United States. Thus, when offsetting the use of propane, substantially more cost savings will be made. Specifically, $20 \mathrm{gal} /$ wk UVO would yield a monthly energy savings of $\$ 325$, and given that $\$ 0.25 /$ gal UVO disposal is avoided, a total annual cost savings of $\$ 4,150$ would be expected. In this case, a complete ROI would be achieved in less than 4 years. Often however, it is less expensive to use electric heat instead of propane. Electricity delivered at $\$ 0.07$ per $\mathrm{kWh}$, when used at $98 \%$ efficiency, equates to a heating cost of about $\$ 20$ per MMBTU. In this case, a multi-fuel water heater could also be retrofit, though a propane "nurse" tank would be required, thus posing some additional capital and operating costs. Nonetheless, it is very possible that the multi-fuel water heater concept could yield significant cost savings over the continued use of an electric water heater. A similar argument can also be made for water heater appliances that consume heating oil, which typically deliver a heating cost of about $\$ 20$ per MMBTU.

Restaurants are sometimes actually paid for their UVO, but it should be recognized that UVO is a volatile commodity and such market conditions are not the norm. This is especially true for relatively small quantities of UVO, such as $20 \mathrm{gal} /$ wk. Moreover, the market value of UVO will likely decline further in the future as most diesel engine manufacturers are implementing ever-more complex exhaust treatment systems that do not allow the use of biodiesel.

Note that the above analysis does not account for the extreme inefficiencies exhibited by many commercial water heaters at the end of their useful life, which are often laden with rust and scale. Thus, the economic payback outlined herein is considered highly conservative when replacing a spent water heater with a multi-fuel water heater system. 


\subsubsection{Sealed combustion versus atmospheric combustion}

A sealed combustion appliance vents its combustion exhaust directly to the outdoors, and similarly it draws combustion air directly from the outdoors. This contrasts with atmospheric combustion appliances, which draw combustion air from the space and also allow space air to travel up the chimney. If an atmospheric combustion appliance is properly installed in a sealed closet, there should be little exhaust dilution from the conditioned space, and little combustion/outside air infiltration into the conditioned space. However, this is often not the case. in practice the use of a sealed combustion appliance will provide lower space heating/cooling and humidification/dehumidification requirements, in addition to being immune from the harmful effects of low indoor air pressure. Sealed mechanical spaces are not always leak tight and are prone to conducting heat with the adjacent conditioned spaces. Moreover, a sealed appliance closet can be difficult to build correctly and may cost the same as the incremental cost of the sealed combustion appliance.

Even when installed in properly designed and built closets, atmospheric combustion appliances suffer from the following inefficiencies

1. Standby loss. When the burner is off, air can still flow up the flue and remove heat from the heater tank.

2. Excess air flowing past the burner and up the flue during combustion. Because the burner is open to the air, there is no way to effectively control this additional air flow, which carries with it significant quantities of heat. 


\section{Proposed Equipment Installation at JBER}

The multi-fuel water heater system proposed for JBER was substantially different from that of the target installation described in Section 2.1. Ideally, the decision to install a multi-fuel water heater system was chosen based on technical compatibility and ROI. However, the programmatic requirements of the present ITTP effort specified that the equipment must be installed in an Army-owned building at JBER, which ultimately confined the equipment host site to JBER Bldg. 655 , the primary dining hall and recreation center.

\subsection{Overview of proposed equipment installation}

As mentioned, JBER Bldg. 655 was determined to be the only plausible host site for demonstrating the multi-fuel water heater equipment for this work because:

1. It was known to operate and produce UVO year round, regardless of military deployment status (at least before the merger of Fort Richardson and Elmendorf Air Force Base).

2. JBER has sufficient ownership and control over Bldg. 655 to implement a retrofit installation and to revise maintenance protocol.

The installation was initially to be configured such so the system would consume only the UVO produced in Bldg. 655. However, an additional consideration was that the multi-fuel water heater system may eventually be used as a centralized system that could burn UVO derived from other sources on the installation. This centralized system would require additional UVO filtration, storage, and transport logistics. Thus, the primary focus of this work was to establish a standalone system in Bldg. 655 that could be adapted in the future for use as a centralized system.

JBER Bldg. 655 is a two-story structure that has all of its mechanical rooms located on the basement level, which exists predominately below grade. The kitchen and associated frialators are located on the main level, which serve the Gold Rush Inn cafeteria. Through consultation with kitchen staff and building maintenance personnel, it was collectively determined that the best location for the multi-fuel water heater was in a basement mechanical room located adjacent to the existing natural gas boiler 
and steam-domestic water heat exchange system (which are in separate but also adjacent mechanical rooms). Hard pipe would transport UVO from the three cooking oil frialators, which have a capacity of approximately 13 gal each, to the heated UVO storage tank, which would be positioned next to the multi-fuel water heater. Each frialator is drained once per week, yielding a UVO supply of nearly 40 gal per week.

A significant consideration in selecting the INOV8 multi-fuel water heater to be used for this work was in selecting a unit that could physically be moved into the mechanical room. There was concern that the larger INOV8 water heater would have difficulty passing through a tight corner that transitioned into a downward flight of stairs. However, calculations showed that the smaller INOV8 water heater could consume all of the UVO produced onsite JBER, so the smaller INOV8 model was selected for both its technical capabilities and more convenient size.

Although the hot water consumption profile for JBER 655 was not known exactly, but the heat duty provided by the existing heat exchange assembly was substantially greater than the rate of hot water that could be produced by the INOV8 HW210 water heater, and much more than that which could be produced by the available UVO supply. As such, it was collectively decided that the HW210 water heater would be tied into the domestic water heating system upstream from the existing steam-water heat exchange assembly. The multi-fuel water heater would preheat the incoming domestic water that feeds the steam-water heat exchange assembly.

The cost savings of the proposed multi-fuel water heater system would be quantified by a reduction in natural gas consumption by the existing Burnham model V1114 (3392 MBH max output) steam boiler. Additional benefits of the proposed installation would include a reduction of UVO handling and a reduction of UVO disposal costs. However, grease trap waste would still require pickup, and therefore the current UVO disposal system would still be required to remove grease trap waste from JBER 655 .

\subsection{UVO filtration, piping, and storage}

An additional disadvantage of the proposed installation in comparison to those made in the private sector is that JBER hires onsite contractors to provide O\&M, instead of relying on the relatively lower cost of installation 
staff (where applicable). This was expected to notably increase the cost of UVO filtration maintenance. Additionally, new kitchen personnel are frequently rotated in and out of JBER 655 so any new or complex O\&M protocols could be problematic. As such, it was a major design objective to reduce the filtration system maintenance requirements and to automate the system's function as much as possible.

Figure 3-1 shows the three cooking oil frialators used in the Gold Rush Inn kitchen. To help maintain cooking oil quality, kitchen personnel periodically run the cooking oil through a Pitco drain filter (Figure 3-2). To keep O\&M protocol changes and UVO filtration system maintenance to a minimum, spent UVO would be pre-filtered with the Pitco drain filter before being filtered and disposed of through the UVO filtration system.

The UVO filtration system, namely the UVO pump, filters, valves, hose and pickup wand, were housed in a portable cart. This filtration cart was designed to fit to the left side of the frialator assembly (Figure 3-3). The frialators are on castor wheels so that they can be moved for cleaning. Similarly, the filtration cart was designed to be readily moved. If necessary, the filtration cart could also be stored in a closet when not in use. However, the hard pipe connection leading to the UVO storage tank would be a permanent fixture. The filtration cart would accept hot UVO from the frialators, eliminate the need for staff to wait for UVO to cool, and enable efficient and low maintenance filtration by capitalizing on low UVO viscosity and surface tension.

The UVO pump consists of a Viking SG-0510 Power Transfer Unit, which can pump up to 8 gal per minute. The UVO pump can handle temperatures of up to $450^{\circ} \mathrm{F}$, and its pressure and fluid viscosity capabilities far exceed requirements. The filter cartridges consisted of commercial-grade Shelco brand RHS-786 VB filter housings with 75 micron stainless steel filter cartridges fitted with viton gaskets. The existing Pitco drain filter, to be used as a pre-filter, has a 120 micron mesh screen.

As illustrated in Figure 3-3, spent UVO is pumped from the kitchen/frialator area to the UVO storage tank. The hard pipe would thus transport UVO from the main level and into the basement of JBER 655, spanning a horizontal distance of approximately $50 \mathrm{ft}$. Core drilling through the floor and also through several walls would be necessary to provide this connection. 
Figure 3-1. Fryer equipment in Bldg. 655.

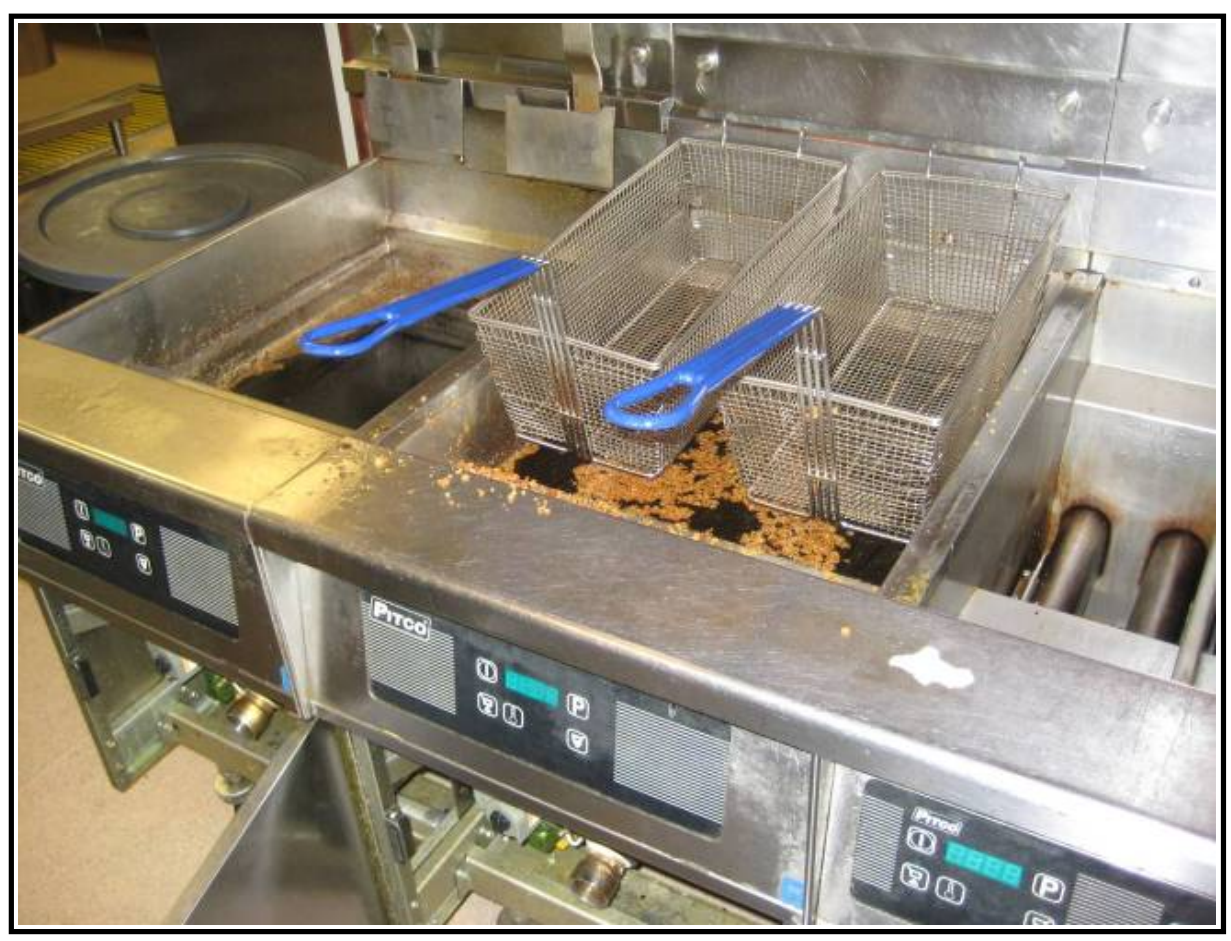

Figure 3-2. Pitco pre-filter with wand and Teflon ${ }^{\mathrm{TM}}$ hose.

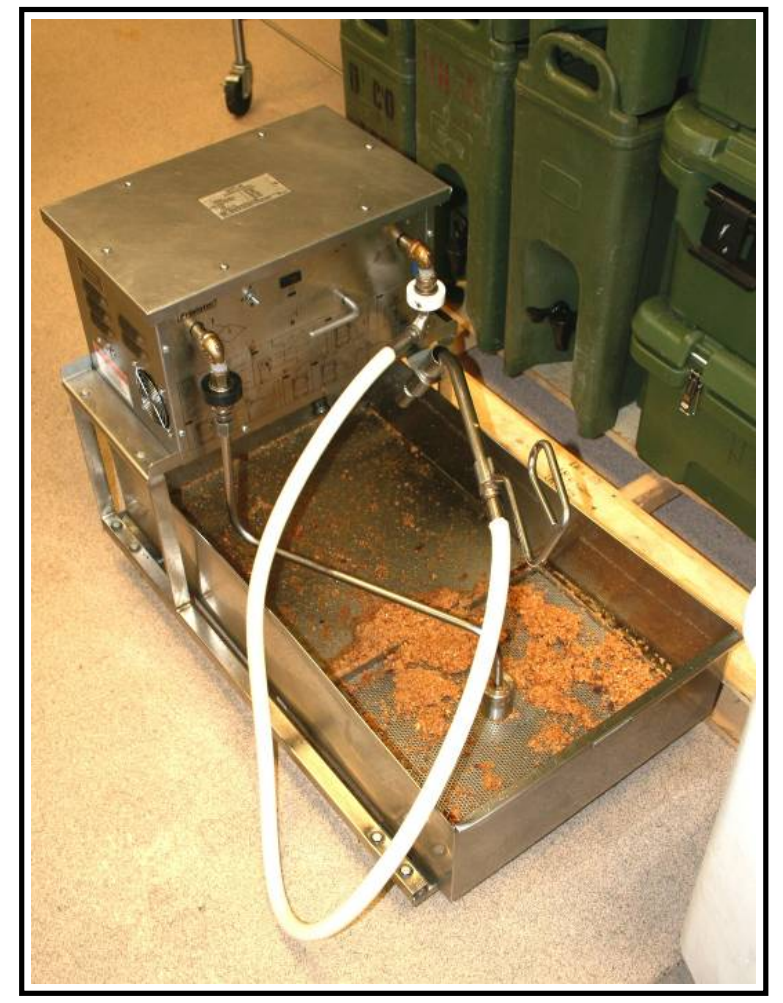


Figure 3-3. Schematic indicating UVO pump/filtration cart, hard pipe and storage tank.

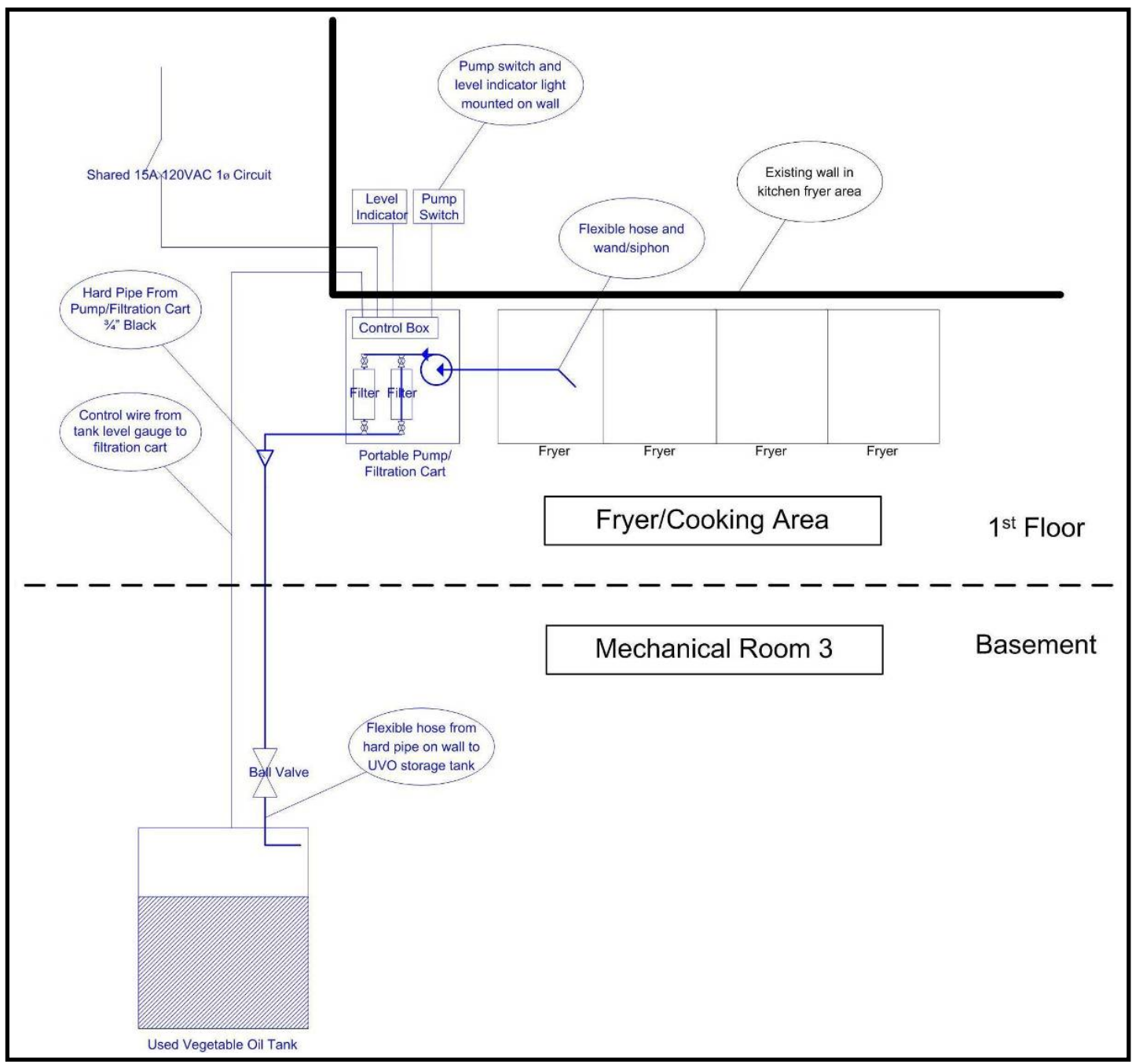

Significant UVO storage tank development was required for the proposed JBER 655 installation. The UVO tank was designed to accommodate the high temperature UVO, and to provide tank heating, secondary containment, fill level detection and fill level feedback to the UVO pump. All tank and filtration system materials required high temperature resistance, and chemical compatibility with UVO.

Given that UVO could be pumped out of the frialators at up to $400{ }^{\circ} \mathrm{F}$, the nominal (average) UVO tank inlet temperatures (after being sent through and partially cooled by the hard pipe) were calculated and verified by analytical estimation. Given 20 gal of hot fry oil initially at $400{ }^{\circ} \mathrm{F}$, and $40 \mathrm{ft}$ of 3/4-in. hard pipe, it was calculated that the UVO would cool only by about 
$25-40{ }^{\circ} \mathrm{F}$. Given various UVO flow rates and hard pipe wall thicknesses, the range of nominal UVO outlet temperatures are:

- Schedule 40 pipe, 4 gpm: nominal oil outlet temp $=375^{\circ} \mathrm{F}$ Oil outlet temp range: 196 to $386^{\circ} \mathrm{F}$

- Schedule 40 pipe, 2 gpm: nominal oil outlet temp $=367^{\circ} \mathrm{F}$ Oil outlet temp range: 190 to $373{ }^{\circ} \mathrm{F}$

- Schedule 80 pipe, 4 gpm: nominal oil outlet temp $=369^{\circ} \mathrm{F}$ Oil outlet temp range: 193 to $386^{\circ} \mathrm{F}$

- Schedule 80 pipe, 2 gpm: nominal oil outlet temp $=361{ }^{\circ} \mathrm{F}$ Oil outlet temp range: 150 to $373^{\circ} \mathrm{F}$.

Ultimately, the heat capacity of UVO is about 5 times that of carbon steel, and assuming 20 gal of oil is pumped at a time there will be about $150 \mathrm{lb}$ of oil transferring heat to about $45 \mathrm{lb}$ of steel (given $3 / 4-i n$. schedule 40 pipe). Therefore, this amount of oil will readily heat the steel pipe and storage tank, while losing only a relative small quantity of heat.

As such, a 55-gal, corrosion resistant steel drum was obtained as the UVO storage tank. An 85-gal steel overpack drum was obtained for secondary containment, and also for facilitating a heat conduction medium between the UVO tank and hot water loop. Specifically, silicone oil would be used to fill the bottom 8-10 in. of the overpack drum, which would encapsulate the heated water coil that surrounds the bottom of the 55-gal UVO tank. Sonce copper tubing should not be used in intermittent contact with UVO, the heated water line was placed outside the 55-gal UVO drum. The external hot water coil placement also simplifies the task of cleaning out the fine particles that will settle in the 55-gal UVO tank.

The 55-gal UVO drum fill spigot terminates to the side of the tank so as to reduce the amount of air that could become entrained in the UVO supply (Figure 3-3). In some circumstances the fill spigot would be terminated near the bottom of the tank. However, the hard pipe extends from the main level frialators to the basement level UVO tank, and thus the UVO piping would self-drain and fill with air. Because of this, it was determined that the tank spigot would be orientated such that UVO would run down the side of the UVO tank, to minimize the infiltration of air bubbles into the UVO supply. An oil suction line extending from the water heater is used to draw UVO from 6 in. off the bottom of the tank to enable draining 
the tank without picking up fines from the bottom of the tank. An electromagnetic float level is used to relay one of two fill indicator signals to a lighted panel located near the pump control box. Red and yellow indicator lights relay half-full and full tank readings to the user, respectively.

\subsection{Domestic water tie-in and mechanical room layout}

The multi-fuel water heater would be tied into Bldg. 655's domestic water line after the existing water softener (and backflow preventer) and before the two (redundant) Leslie E-60oL model steam-water heat exchangers. The multi-fuel water heater would be included in (or would bypass) the domestic water line through the use of manually operated gate valves. All of the hot water pipe and the UVO pipe would be insulated.

The mechanical room that was selected to receive the multi-fuel water heater was located approximately $20 \mathrm{ft}$ from the existing heat exchange assembly. Figure 3-4 shows a conceptual schematic of the multi-fuel water heater installation. Within this schematic, blue indicates new hardware and black indicates existing hardware. Core drilling through at least one wall was necessary to achieve this connection. The conceptual illustrations shown in Figure 3-4 are not to scale, nor do they indicate exact room or equipment orientation. Figure 3-4 additionally depicts aspects of the exhaust vent and combustion air system, which is discussed further in the following section.

For the proposed installation, the UVO tank would be located within a few feet of the water heater, which is desired to prevent the UVO from cooling and gelling in the fuel delivery line. The water heater burner has its own fuel pump, which draws and circulates UVO to and from the UVO storage tank. A portion of the heated UVO is circulated back to the UVO tank, along with any vapors generated. In some installations space requirements dictate that UVO must be stored a distance from the water heater, in which case an additional UVO boost pump can be required. This configuration may also necessitate an oil regulator to reduce the UVO pressure to the burner. Although, as shown in Figure 3-5, there was sufficient contiguous space in Mechanical Room 3 to collocate the multi-fuel water heater with the UVO storage tank. 
The air compressor used to provide nozzle air consisted of an Alton brand ATo1 201-3 compressor, which can supply 2.2 CFM air at 90 psi. The HW210 water heater requires a minimum of 2.0 CFM air at 45 psi, which has its own air pressure regulation and moisture trap (although use of a desiccant air filter is recommended). The regulator that feeds compressed air to the fuel nozzle is set at 14 psig.

\subsection{Sealed combustion vent and draft inducer}

The placement of the exhaust vent is an important consideration in determining where to place a water heater or boiler. Often (even in renovations), boiler rooms are placed on the highest level to avoid the need for long chimneys and fire resistant ducts from lower levels. Additionally, boiler rooms must in general be separated from other mechanical rooms. Boiler rooms must have a certain degree of fire resistance and all of its openings (piping, electrical conduits) must be closed according to applicable regulatory codes and standards.

As shown in Figure 3-5, there was only one plausible location for the placement of the multi-fuel water heater in JBER 655, which unfortunately required the implementation of long horizontal and vertical vent sections. Additionally, it was not possible to isolate the multi-fuel water heater and UVO storage tank from various HVAC and grease trap equipment.

Most notably, there were substantial concerns regarding the long exhaust vent, especially the horizontal section since horizontal vents used with oilburning appliances tend to be problematic. To improve the low draft resulting from long and tortuous venting systems, a draft inducer must be used, which can also cause problems. Specifically, if the relay in the water heater's electrical junction box starts the draft inducer too soon, it can cause lift off of the flame, and if it starts too late it can disrupt the flame by imposing a negative pressure in the combustion chamber. Thus, aside from the additional capital and installation cost expenditures of the long and complex vent, the use of a draft inducer will further increase technical risk and maintenance requirements. 


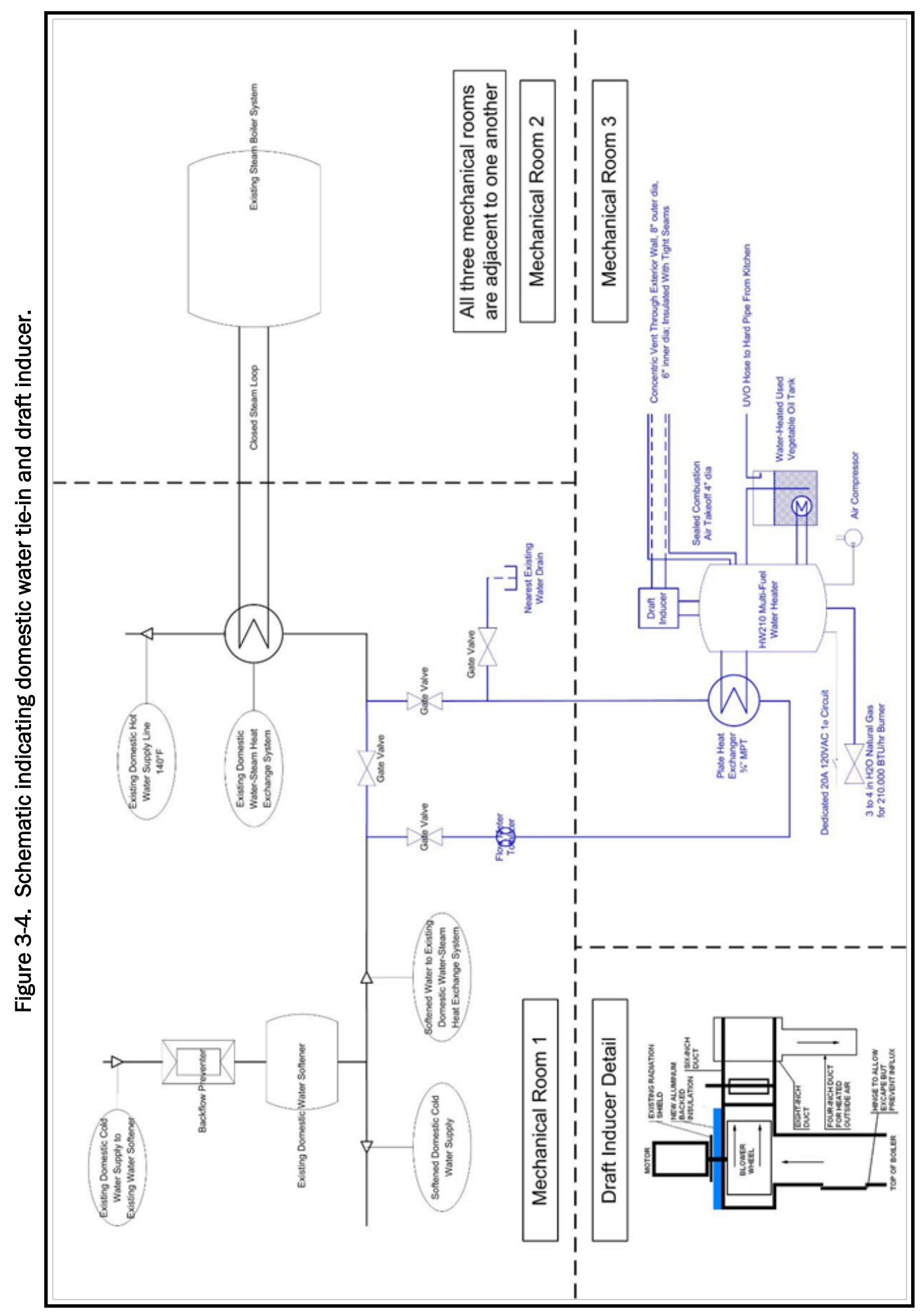


Figure 3-5. Available footprint for proposed multi-fuel water heater installation.

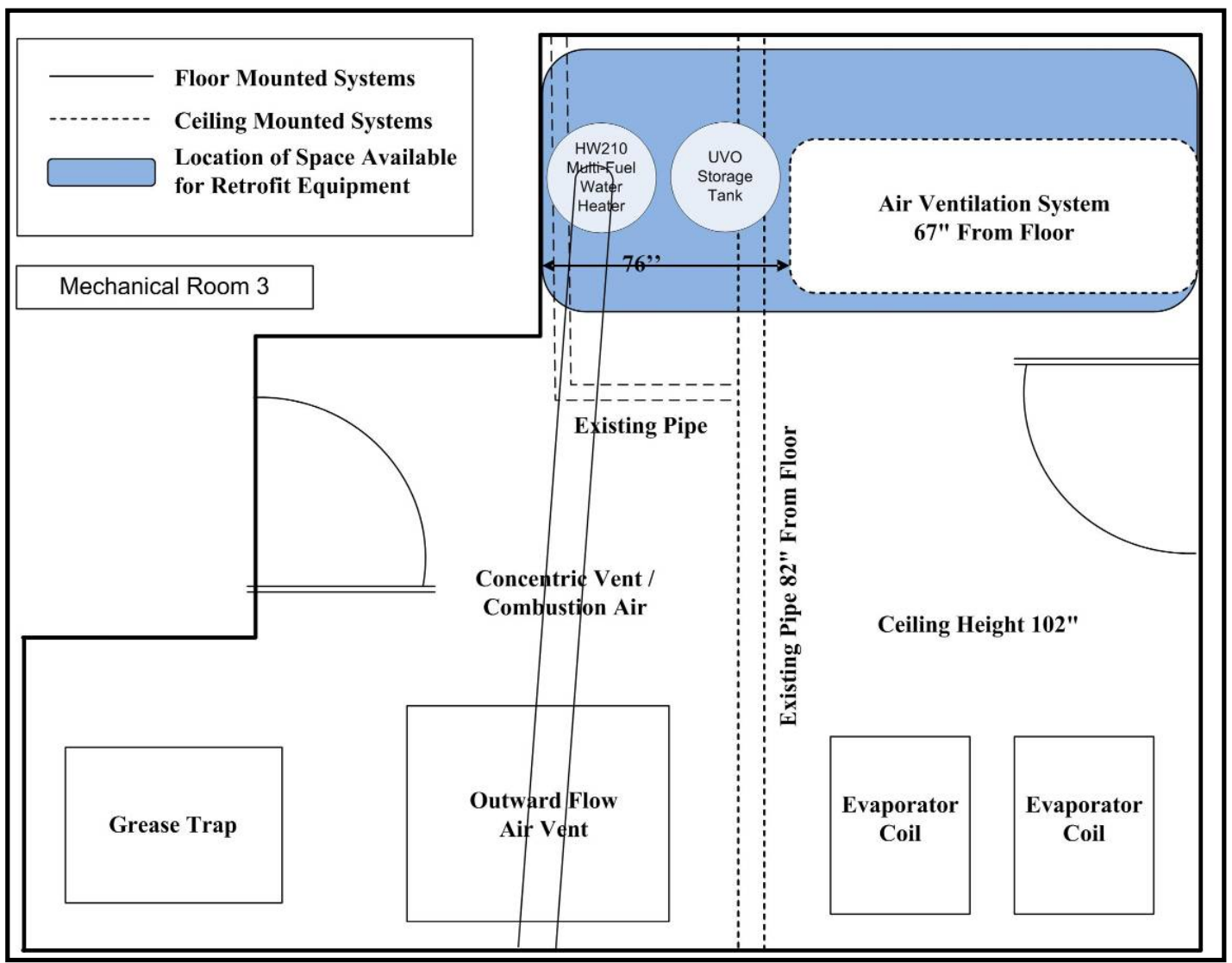

A chimney that does not provide adequate draft will cause the following problems

1. Dirty combustion that yields black smoke

2. Soot/ash buildup inside the water heater

3. Buildup of unburned oil on the flame retention head

4. Back pressure from the exhaust that will carry soot/ash backward into the burner housing causing nozzle blockages

5. Accumulation of unburned oil inside the combustion chamber.

When a draft inducer must be used, INOV8 recommends that it be installed just above the double acting draft control in the next vertical section from where the water heater flue pipe enters. The purpose of the double acting draft control is to quickly release pressure in the event of a puff of gas caused by delayed ignition. It also helps to control the draft by smoothing out pressure variations caused by the draft inducer and wind gusts and other environmental factors. 
The draft inducer fan should be installed such that the blades are in the natural flow of the exhaust. It is best to avoid mounting the fan in horizontal sections to prevent: (1) accumulation of soot/ash on the blades, (2) exposure of the fan to excessive heat, and (3) the need to support the fan mechanically.

It was not possible to install the draft inducer next to the exterior wall to eliminate the need to seal the indoor vent seams. In JBER 655, the draft inducer would be configured in the vertical section above the water heater (Figure 3-6). This configuration would cause a positive exhaust pressure in much of the indoor/horizontal vent, which would require indoor vent seams to be sealed tight to prevent exhaust gas leakage and to mitigate potential fire hazards.

The horizontal vent section was approximately 25 to $30 \mathrm{ft}$ in length. Thus, the Tjernlund HS2 Power Venter was recommended by INOV8 to maintain the specified draft conditions. Figure 3-7 shows the draft Tjernlund HS2 flow curves. To maintain the draft conditions specified by INOV8, the HS2 Power Venter has an adjustable louver that can be fine-tuned to maintain the required draft specification.

Figure 3-6. Indication of concentric sealed vent, combustion air boot and draft inducer.

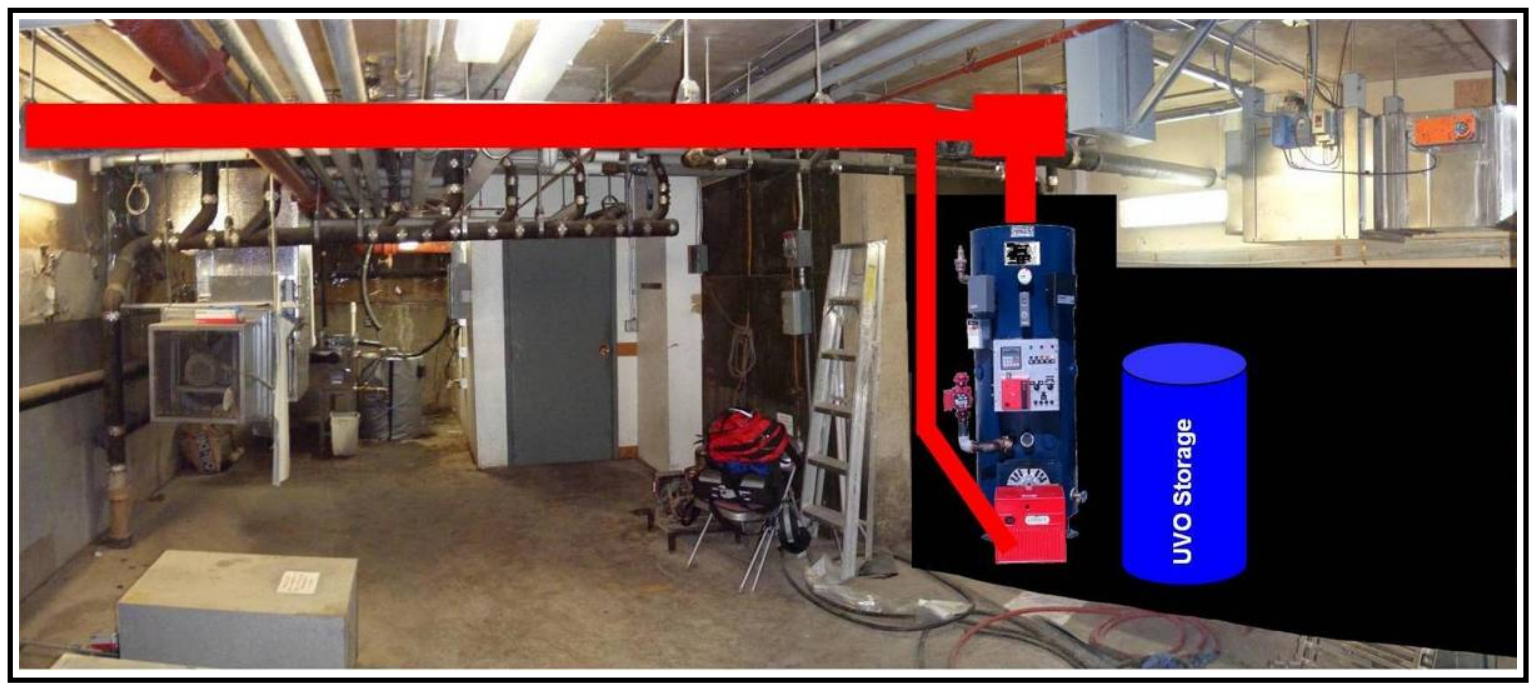


Figure 3-7. Tjernlund HS2 Power Venter performance curves.

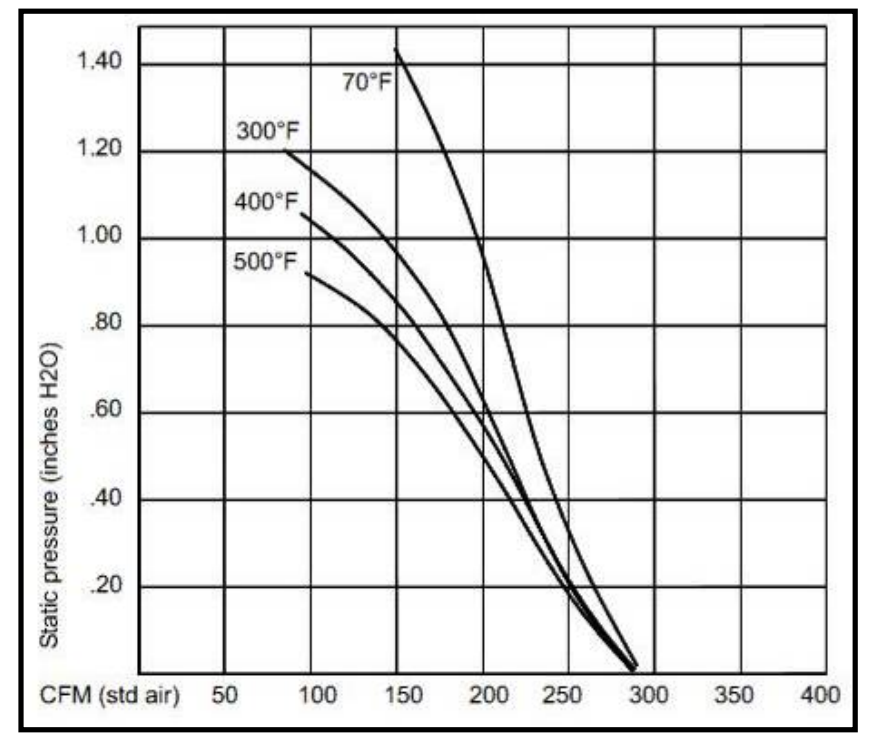

Since code stipulates that continuous horizontal vent runs in excess of $30 \mathrm{ft}$ require a condensate drain, there was concern that a condensate drain and pump would be necessary. Since the drain system at JBER is composed of carbon steel, the condensate would have to be neutralized before draining. Although it was not verified definitively, it appeared that the proposed horizontal vent run would be a few feet short of requiring a condensate drain, pump, and neutralizer.

Although UVO does not contain the level of detergents and other ash-producing constituents found in used motor oil, the production of soot and ash was still a notable concern for this installation. JBER engineering was additionally concerned about the height and grade of the horizontal vent section, which appeared to have marginal clearances.

Figure 3-8 shows the only feasible vent penetration through the exterior wall given the crowded nature of Mechanical Room 3. Figure 3-8 clearly shows that a gas regulator, an air grille, two windows, and the anticipated snow line all have very marginal, if not inadequate, clearances in relation to the proposed vent penetration. In collaboration with JBER engineering it was determined that the presence of these fixtures eliminated the prospect of having a side vent termination, and the prospect of drawing outdoor combustion air from this location. This was a crucial and expensive ramification, as it stipulated that the exhaust vent would have to be extended vertically to a height exceeding the JBER 655 roofline. 
Figure 3-8. External wall shown with vent penetration and exhaust stack.

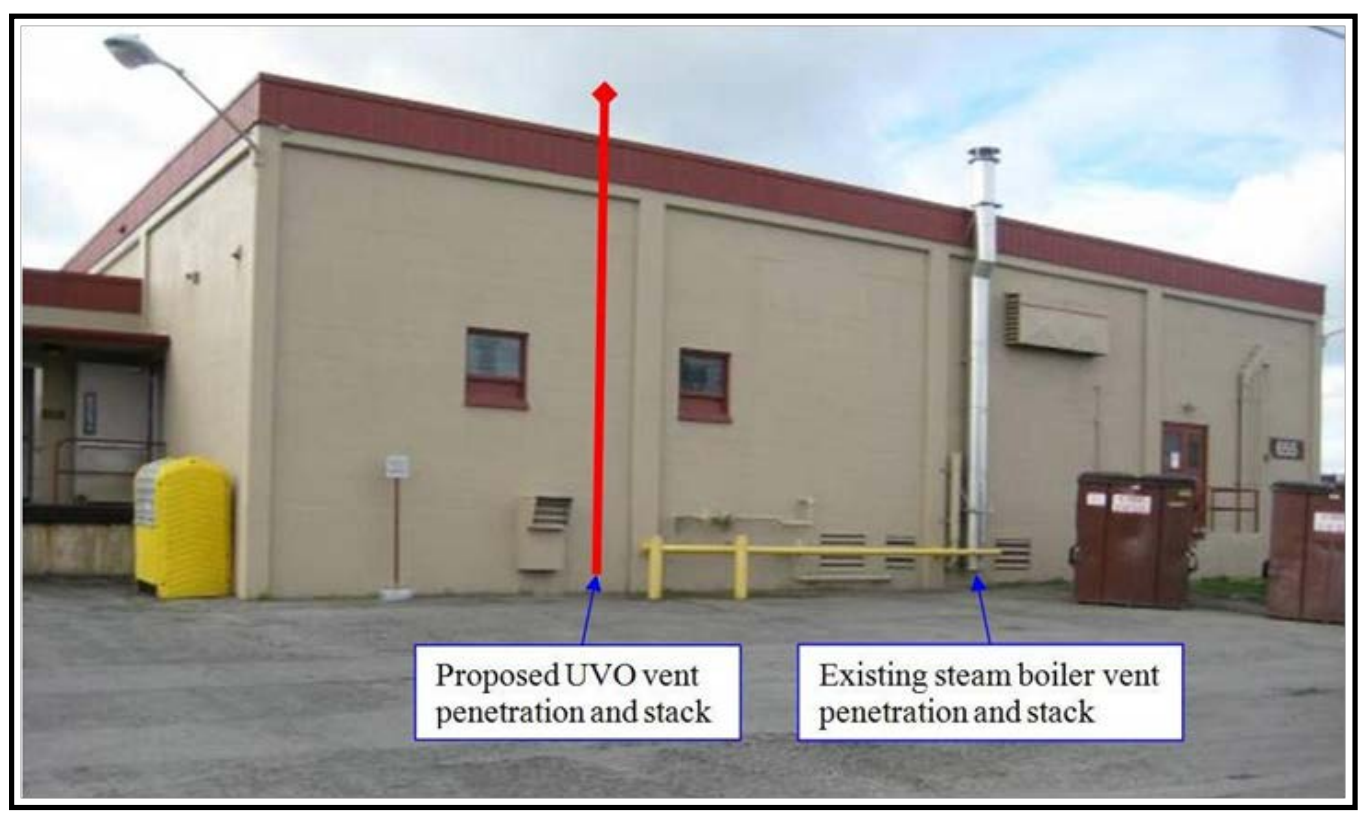

Given the substantial importance of the vent system, local contractors were consulted for additional feedback. Moore (personal communication. January 2010) stated that "due to the really tight draft parameters, a side vent termination should be implemented given the high potential for condensate within the proposed vertical vent section." Unfortunately, no way was found to circumvent the need for the vertical vent section.

The length of the vertical vent section was approximately $35 \mathrm{ft}$, thus yielding a total vent length of about $60 \mathrm{ft}$. Additionally, the exhaust would be subject significant cooling from the incoming combustion air, and suffer pressure drop due to numerous vent bends. To help accommodate the excessive length and pressure drop, INOV8 specified the vertical exhaust duct to be 2 in. larger than the indoor exhaust duct, yielding a vertical vent diameter of 8 in.

INOV8 also recommended that the entire vent (indoors and out) be insulated. Insulation was not required for the horizontal run; however, insulation was recommended to keep the exhaust temperature as high as possible and to retain as much heat as possible to preheat the incoming air. Ideally, the sealed combustion air/exhaust vent system would preheat the combustion air to $200-250^{\circ} \mathrm{F}$, to maintain the necessary high temperature UVO combustion zone. 
Several unresolved problems remained

1. There was no clear alternative location for a vent to draw combustion air to the proposed vent on the outside of the exterior wall, which was near the existing gas regulator.

2. There was some concern about installing the water heater in the same room with other equipment that was not fire resistant.

3. It was unclear if the proposed installation could meet all pertinent codes and regulations.

Nevertheless, the proposed equipment installation, as outlined herein, was used to solicit quotations.

\subsection{Cost of proposed equipment installation}

Despite the various uncertainties regarding local codes and regulations, a local mechanical contractor was solicited to provide a quotation for the installation of the multi-fuel water heater system. The following sections summarize the scope of work as defined for this project.

\section{The general contractor will be responsible for the following:}

1. Setting of the multi-fuel water heater (equipment provided), including the installation of a dedicated 20 amp circuit and natural gas feed

2. Installation of the domestic water tie-in loop

3. Installation of the sealed concentric exhaust vent/combustion air supply and draft inducer (provided)

4. Installation of the hard piping and control wiring/conduit from the fryer area to the UVO storage area (UVO hose provided for the tank connection).

\section{Chimney installation:}

1. The concentric vent is to be fabricated with tight indoor seams yet must also permit periodic inspection and maintenance.

2. The outer fresh air duct is to be terminated at the outside wall.

3. The chimney size is to be increased at that point to an 8-in. insulated duct, which shall continue to the top of the roofline.

4. A simple chimney cap, i.e., a Breidert cap, is to be installed, which prevents rain entry, but does not create pressure.

5. The chimney is to be fabricated per guidelines used for oil-burning equipment. 
INOV8 personnel will arrive onsite JBER near the completion of the installation and will commission and adjust all of the installed equipment. INOV8 personnel will be responsible for connecting the draft inducer control wiring with the water heater, and the UVO pump control wiring with the UVO storage tank. The contractor is responsible for all code compliance and necessary contractor/subcontractor registration and insurances.

After multiple site visits and technical iterations, the following (final) quotation was obtained:

Install owner provided equipment, supply and install all-fuel stack, welding of inner liner to water heater, 8-in. outer liner with standoff for combustion air, domestic water piping, UVO line piping, insulation, water heater wiring, conduit to 2nd floor for controls, man-lifts, wall hood, and core drilling.

\section{NOT TO EXCEED THE SUM OF: \$ 45,168.OO}

The quotation specifically excludes:

- Controls, start up or commissioning

- Cost of bond, builders risk insurance, and waiver of subrogation.

The work to be performed was quoted given "time and material not to exceed" work conditions. Thus, the plumbing and electrical may have turned out to be less. However, the sheet metal and core drilling were to be subcontracted and thus were taken as hard numbers. It was unclear if time and a half or double time was considered for the work to be performed after hours, as any work that involves disrupting water supply in JBER 655 must be performed after regular business hours. Nonetheless, Table 3-1 lists an itemization of the general contractor's quotation assuming a nominal labor rate of $\$ 98 / \mathrm{hr}$.

A second sheet metal quotation was also obtained, though it was only $\$ 700$ less than the first quotation. In short, the capital cost combined with the installation cost was greater than the total cost savings anticipated over the life of the equipment. 
Table 3-1. Itemized general contractor's quotation.

\begin{tabular}{|l|r|}
\hline Description & \multicolumn{1}{|c|}{ Price } \\
\hline Plumbing and setting & \\
\hline Material & $3,200.00$ \\
\hline 110 Man-hours & $10,795.00$ \\
\hline Electrical (including low volt controls and line volt) & \\
\hline Material & $2,200.00$ \\
\hline 60 Man-hours & $5,888.00$ \\
\hline Sheet metal & $19,635.00$ \\
\hline Insulation & $1,550.00$ \\
\hline Core drilling & 900.00 \\
\hline Misc. and general conditions & $1,000.00$ \\
\hline Total Price & $\mathbf{\$ 4 5 , 1 6 8 . 0 0}$ \\
\hline
\end{tabular}

\subsection{Efforts to reduce the equipment installation cost}

A significant effort was made to decrease the cost of the proposed equipment installation, for the benefit of the present work and for future multifuel water heater installations. As indicated in Section 3.5, the single largest cost of the proposed JBER 655 installation, including the capital expenditure of the equipment, was that of the long and complex vent system.

Incidentally, the long and complex vent system was also considered to be the greatest liability and cause for concern. The use of a custom-made vent system was not criticized by JBER engineering. However, custom-made vent fittings that are not approved by the Underwriters Laboratory would likely draw scrutiny over time. As such, a significant focus was placed on locating commercially available vent fittings that are UL listed for oilburning appliances. The use of such commercial fittings would reduce installation cost and the potential liability of equipment installations.

As implied, an extensive review of commercially available vent fittings was performed. It was found that oil-approved, sealed combustion vent fittings that have the necessary inside/outside diameters specified by the INOV8 do not exist. However, as shown in Figure 3-9, the UL-listed Heatfab Saf-T vent CI Plus fittings could easily be adapted for use with INOV8's multifuel water heater equipment. 
Figure 3-9. Heatfab Saf-T Vent CI Plus double wall vent.

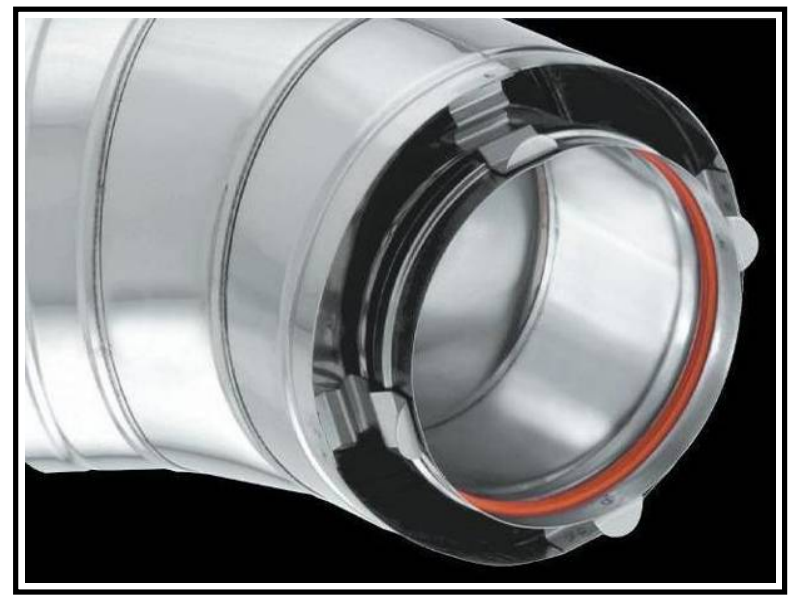

The Heatfab Saf-T Vent CI Plus fittings are double wall vents and are UL listed for use with oil and gas burning equipment with continuous flue-gas temperatures that do not exceed $570^{\circ} \mathrm{F}$ (Type L). The CI Plus fittings are constructed with AL294-C stainless steel, which can tolerate high levels of condensate. As mentioned, the CI Plus fittings are not intended for sealed combustion appliances, but the manufacturer confirmed that it could be used for this purpose. The CI Plus product line is the only existing commercially available, UL-listed, oil/gas approved vent that has the approximate dimensions necessary for integration with INOV8 multi-fuel water heater technology.

As the CI Plus vent fittings are not intended for sealed combustion applications, Heatfab does not currently offer a combustion air standoff. However, it was also confirmed that Heatfab will produce this fitting through custom order. If necessary, they also offer a CI Plus vent flow regulator, which may be required when the use of a draft inducer is necessary.

Approximate distributor prices for several of the essential (and non-essential) concentric vent components were obtained from one of Heatfab's distributors

1. 36 -in. straight length CCAo6L36 (x6, essential) $=\$ 205$ each

2. Long adjustable length CCAo6AJ ( $\mathrm{x} 1$, essential) $=\$ 175$ each

3. In-line drain section CCAo6DRN ( $\mathrm{x} 1$, non-essential) $=\$ 165$ each

4. In-line probe section CCAo6PRB (x1, non-essential) $=\$ 136$ each

5. Vent flow regulator CCAo6BG $(\mathrm{x} 1$, non-essential $)=\$ 230$ each

6. In-line damper CCAo6DMP (x1, non-essential $)=\$ 588$ each. 
For long and complex vent systems, it remains evident that the cost of the vent system is extremely important. Given the proposed JBER 655 installation, the commercially available Heatfab CI Plus vent fittings would have cost an estimated $\$ 4,000$ to $\$ 5,000$ in addition to the cost of multiple custom fittings and of course the installation of the vent system. Thus, the cost savings of using the Heatfab fittings as opposed to having a completely custom-made vent system is estimated to be on the order of $50 \%$. Additionally, the value of using a UL-listed vent would have also been gained.

The use of the UL-listed Heatfab CI Plus vent fittings (or similar) was found to be a crucial element to streamlining and reducing the cost and liability of the multi-fuel water heater system. To a lesser degree, reducing the cost of the UVO filtration, storage, and peripheral components is also necessary.

\subsection{Decision to abandon the proposed equipment installation}

Ultimately, the proposed JBER 655 installation was abandoned given the excessive technical complexity and risk, high installation cost and insufficient economic return, questionable code compliance and other technical uncertainties and liabilities. 


\section{Potential Impact to U.S. Army}

The benefits of the multi-fuel water heater concept are that it can provide a simple and reliable means of UVO disposal that reduces non-renewable energy usage and associated pollutant emissions. The multi-fuel water heater concept directly addresses the Department of Defense's (DoD's) mandate to implement Executive Order 13423, which sets clear goals for energy conservation and the use and purchase of renewable energy. The use of this technology can help the Army meet the goals of the Army Energy Strategy, specifically, to reduce energy consumption and increase the use of renewable energy.

Demonstrating the successful implementation of this concept will enable the DoD to use UVO as a reliable fuel, thereby reducing or eliminating UVO disposal costs while decreasing fossil energy consumption and decreasing the carbon footprint of each military installation. DoD will always have a need for hot water, especially in restaurants and dining facilities, and the approach to use UVO to assist in this process represents a significant improvement in energy efficiency and in the efficient use of personnel. The reuse of UVO as fuel enables facilities to be more self-reliant and economically competitive as energy prices fluctuate and increase over the long-term.

\subsection{Facility compatibility}

As illustrated by this work, the installation of a multi-fuel water heater system in a large, multi-level building can be extremely difficult and expensive. Military dining halls are typically located in large buildings that implement large and relatively complex heating systems, and are therefore not well suited for implementing the multi-fuel water heater concept. Additionally, the amount of UVO produced versus the amount of hot water consumed in dining halls is not well matched. Moreover, recent studies indicate that there is a substantial effort to completely eliminate deep fat frying techniques from Army mess halls.

Also illustrated by this work, the implementation of a simple and entirely vertical vent system is paramount to avoiding the need for a costly, draft-induced vent system that exhibits an increased technical risk and maintenance requirements. As such, the multi-fuel water heater concept is ideally 
used for its intended purpose, namely for the benefit of standalone restaurants where the water heater can provide all of the building's hot water needs. Standalone restaurants can facilitate much simpler equipment installations, which are also expected to continue the use of cooking oil frialators.

With regard to maintenance, and specifically the maintenance of the filtration system, manpower can be prohibitively expensive when the additional (new) tasks must be performed by a subcontractor. This makes it especially important to minimize, and where possible to automate, the multi-fuel water heater system's maintenance requirements for military installations.

It should also be considered that, at the end of a typical water heater's life, it is generally laden with rust and scale and operates very inefficiently. Thus, the economic payback can be great when an existing water heater is replaced at the end of its useful life. This scenario should be the focus for retrofit installations. However, the ideal scenario is when the multi-fuel water heater is installed during initial building construction. Not only is space at a premium in kitchen facilities but the layout of equipment and piping may be optimized when it is considered from the beginning. Each retrofit installation will have its own complexities, difficulties, and confusions. When integrated into new construction plans, the architect can design an optimal layout for operators and proximity of the associated multifuel water heater system hardware. If the multi-fuel water heater system and its operating protocols are considered during the architectural phase, better economic payoffs and overall success will be achieved.

\subsection{Army and Air Force Exchange Service (AAFES) and Morale, Welfare, and Recreation (MWR)}

It is recommended that the multi-fuel water heater concept be used in standalone restaurants, such as fast food franchise stores, particularly those operated by the AAFES and the Morale, Welfare and Recreation (MWR) organizations. The military's franchise restaurants are operated by the AAFES and MWR agencies and were thus identified as the most notable market for the multi-fuel water heater technology. AAFES currently operates more than 2,200 fast food restaurants, including large franchises such as Burger King and Taco Bell. 


\section{Conclusions and Recommendation}

This work developed the concept of using reconditioned UVO as a fuel in a multi-fuel water heater system for implementation into an Army-standard process to effectively and efficiently dispose of UVO produced at military bases. This effort also worked to optimize the design, installation, and capital cost of commercially available equipment so Energy Savings Performance Contractors could easily implement this concept throughout all military facilities, where applicable.

This work evaluated the installation of a multi-fuel water heater installation at JBER Bldg. 655, which houses the Gold Rush Dining Facility, for a retrofit installation with INOV8 multi-fuel water heater equipment. Design plans and cost estimations were established for this installation, which were ultimately not implemented due to excessive technical complexity and high installation cost. Moreover, the proposed installation at JBER was representative of a concept that is expected to become obsolete, as there has been a substantial trend for Army mess halls to eliminate the use of cooking oil frialators.

Nevertheless, the target multi-fuel water heater system arguably represents the simplest and most viable method for implementing a standard protocol to handle and dispose of UVO produced in Army-owned restaurants. It represents a highly efficient UVO-to-energy concept, the use of which rivals the economic return of other UVO disposal alternatives.

This work concludes that, where sufficient technical compatibility exists, and specifically where the replacement of a conventional water heater is possible, the use of UVO for generating hot water is more practical, energy efficient, and economical than competing alternatives.

It is recommended that the multi-fuel water heater concept be used within standalone, fast food franchise stores on military installation that are operated by the AAFES and MWR organizations since the use of cooking oil frialators is an established cooking method at those businesses. 


\section{Acronyms and Abbreviations}

\begin{tabular}{ll} 
Term & Definition \\
AAFES & Army and Air Force Exchange Service \\
ACSIM & Assistant Chief of Staff for Installation Management \\
ANSI & American National Standards Institute \\
Btu & British Thermal Unit \\
CEERD & U.S. Army Corps of Engineers, Engineer Research and Development Center \\
CERL & Construction Engineering Research Laboratory \\
CFM & Cubic Feet per Minute \\
CSA & Canadian Standards Association \\
DoD & U.S. Department of Defense \\
ERDC & Engineer Research and Development Center \\
GDP & Gallons Per Day \\
GPH & Gallons Per Hour \\
GPM & Gallons Per Minute \\
HVAC & Heating, Ventilating, And Air-Conditioning \\
IMCOM & Installation Management Command \\
ITTP & Installation Technology Transition Program \\
JBER & Joint Base Elmendorf-Richardson \\
LHV & Lower Heating Value \\
LTI & Leonardo Technologies, Inc. \\
MBH & 1000 Btu/hr \\
MWR & morale, welfare, and recreation \\
NFPA & National Fire Protection Association \\
NSN & National Supply Number \\
O\&M & Operations and Maintenance \\
OMB & Office of Management and Budget \\
PLC & Programmable Logic Controller \\
ROI & Return on Investment \\
SAR & Same As Report \\
SF & Standard Form \\
TR & Technical Report \\
UL & Underwriters Laboratories \\
USAG & U.S. Army Garrison \\
USD & U.S. Dollars \\
UVO & Used Vegetable Oil \\
WWW & World Wide Web \\
\hline
\end{tabular}




\section{References}

ANSI (American National Standards Institute). 1998. Domestic Gas Conversion Burners. Standard Z21.17/CSA 2.7-M98. $1^{\text {st }}$ ed. Washington, DC: ANSI.

CSA (Canadian Standards Association). 1990. Oil Burners Atomizing-Type. Standard B140.2.1-M98. Toronto: CSA.

Gardin, Stephanie. 2010. Army Leads Way in Turning Trash into Treasure. Washington, DC: Installation Management Command (IMCOM). Accessed 14 March 2011. http://www.army.mil/-news/2010/11/29/48748-army-leads-way-in-turning-trash-into-treasure/.

Lindstrom, Joel, Scott Lux, and Jeff Raun. 2010. Used Vegetable Oil and Used Motor Oil Pollution Prevention Opportunities at Fort Richardson, AK. ERDC/CERL TR10-19. Champaign, IL: Engineer Research and Development Center, Construction Engineering Research Laboratory (ERDC-CERL).

NFPA (National Fire Protection Association). 2011. NFPA 31: Installation of Oil Burning Equipment. Washington, DC: NFPA.

Revelos, Andrew. 2011. Used Cooking Oil Fattens War Chest. Washington, DC: dcmilitary.com: Comprint Military Publications Online, Accessed 14 March 2011, http://www.dcmilitary.com/stories/030311/quanticosentry_28251.shtml. 


\title{
Appendix A: Multi-Fuel Water Heater Emissions Test Results
}

\author{
INOV8's Green Water Heater Combustion Tests \\ Equipment Tested: INOV8 Water Heater Model HW210 \\ Date of Test: June 3, 2010 \\ Fuel Tested: Mix of various fryer oil at room temperature \\ BTU Value: $\quad 130,000$ BTUs per gallon \\ Equipment Setup: Triad verticle steel tube boiler \\ INOV8 G200 gas-oil burner with PLC control \\ Chimney with sealed combustion boot \\ Test Parameters: Oil pressure - high at $10 \mathrm{psi}$, low at $5 \mathrm{psi}$ \\ Air pressure - $13 \mathrm{psi}$ \\ Oil temperature - $150 \mathrm{~F}$ \\ Chimney temperature - $548 \mathrm{~F}$ \\ Ambient air temperature - $76 \mathrm{~F}$ \\ Air boot temperature - $200 \mathrm{~F}$ \\ Test Results:
}
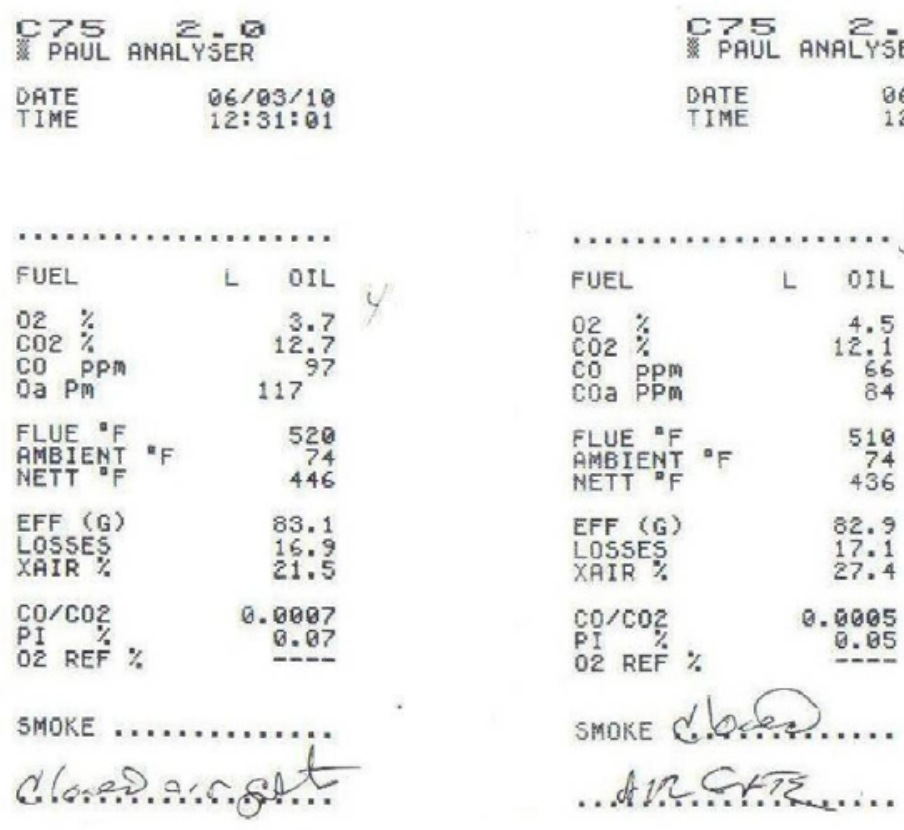

SMOKE C.USF......

..diR...T?E....

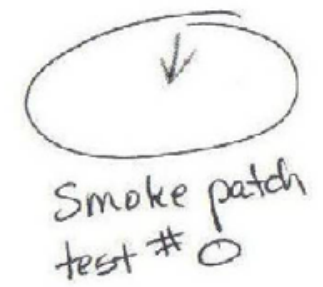




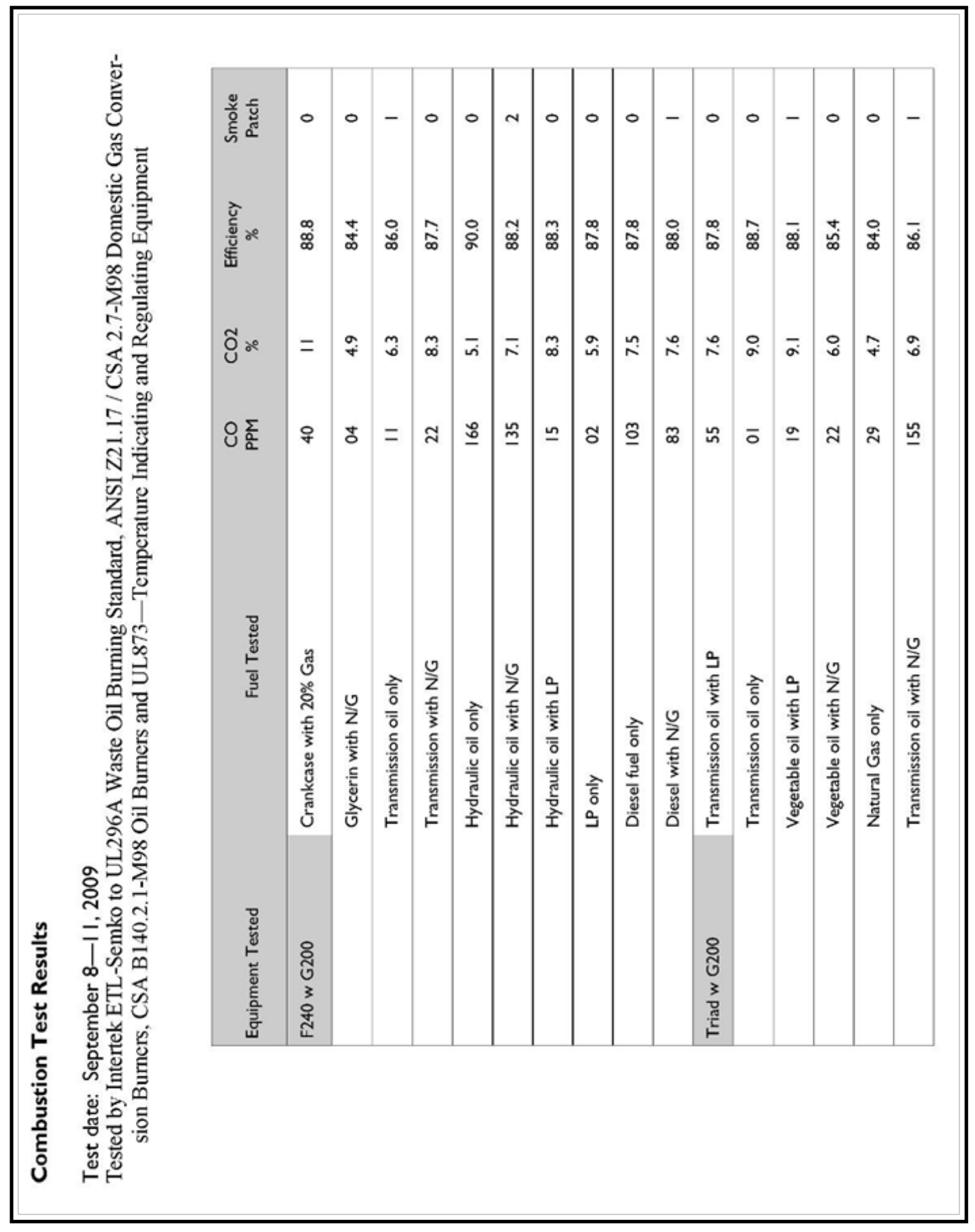




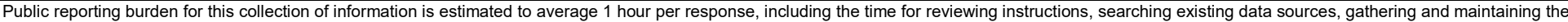

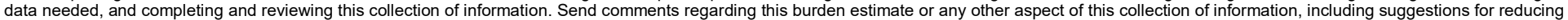

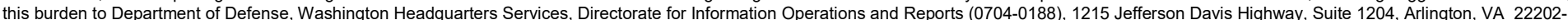

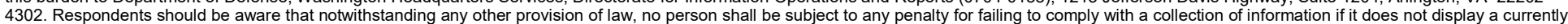
valid OMB control number. PLEASE DO NOT RETURN YOUR FORM TO THE ABOVE ADDRESS.

\begin{tabular}{l|c|c|}
\hline $\begin{array}{c}\text { 1. REPORT DATE (DD-MM-YYYY) } \\
09 / 28 / 2018\end{array}$ & 2. REPORT TYPE \\
\hline
\end{tabular}

4. TITLE AND SUBTITLE

Final

Multi-fuel Combustion Technology for Water Heating with Waste Oil

5a. CONTRACT NUMBER

5b. GRANT NUMBER

5c. PROGRAM ELEMENT

6. AUTHOR(S)

Joel Lindstrom and Scott M. Lux

5d. PROJECT NUMBER

ITTP

5e. TASK NUMBER

FY10-16E

5f. WORK UNIT NUMBER

7. PERFORMING ORGANIZATION NAME(S) AND ADDRESS(ES)

U.S. Army Engineer Research and Development Center (ERDC)

Construction Engineering Research Laboratory (CERL)

PO Box 9005

Champaign, IL 61826-9005

8. PERFORMING ORGANIZATION REPORT NUMBER

ERDC/CERL TR-18-21

9. SPONSORING / MONITORING AGENCY NAME(S) AND ADDRESS(ES)

Assistant Chief of Staff for Installation Management (ACSIM)

600 Army Pentagon

Washington, DC 20310

10. SPONSOR/MONITOR'S ACRONYM(S)

11. SPONSOR/MONITOR'S REPORT NUMBER(S)

\section{DISTRIBUTION / AVAILABILITY STATEMENT}

Approved for public release; distribution is unlimited.

\section{SUPPLEMENTARY NOTES}

\section{ABSTRACT}

Joint Base Elmendorf-Richardson (JBER), AK generates several thousand gallons of used vegetable oil (UVO) annually and expends over $\$ 10,000$ annually to dispose of this waste. Shipping excess UVO over long distances for processing is both expensive and wasteful, when it would be more efficient, economical, and effective to use UVO on site as a fuel to heat water. The Engineer Research and Development Center, Construction Engineering Research Laboratory (ERDC-CERL) and JBER began collaborating in December 2008 to investigate a solution to maximize the benefit of a 4000-gal annual production of UVO into a value-added commodity. This Phase II effort was undertaken to further develop and demonstrate the concept of using the UVO resource by using UVO as fuel for an advanced, multi-fuel water heater that would preheat domestic water entering the existing steam-water heating system in the building that houses the primary dining facility. This work designed a low maintenance UVO filtration and oil-burning system to support an opportunity assessment and pilot-scale implementation for the treatment and salvaging of UVO as a heating fuel at JBER.

\section{SUBJECT TERMS}

Vegetable oils, Recycling (Waste, etc.), Waste products, Vegetable oils as fuel, Water heaters, Joint Base Elmendorf-Richardson (Alaska)

\begin{tabular}{|c|c|c|}
\hline \multicolumn{3}{|c|}{ 16. SECURITY CLASSIFICATION OF: } \\
\hline $\begin{array}{l}\text { a. REPORT } \\
\text { Unclassified }\end{array}$ & $\begin{array}{l}\text { b. ABSTRACT } \\
\text { Unclassified }\end{array}$ & $\begin{array}{l}\text { c. THIS PAGE } \\
\text { Unclassified }\end{array}$ \\
\hline
\end{tabular}

\begin{tabular}{|c|c|c|}
$\begin{array}{l}\text { 17. LIMITATION } \\
\text { OF ABSTRACT }\end{array}$ & $\begin{array}{c}\text { 18. NUMBER } \\
\text { OF PAGES }\end{array}$ & \\
\cline { 3 - 3 } SAR & 56 & \\
& & \\
\end{tabular}

19b. TELEPHONE NUMBER (include area code) 